\title{
Basal insulin combined incretin mimetic therapy with glucagon-like protein 1 receptor agonists as an upcoming option in the treatment of type 2 diabetes: a practical guide to decision making
}

\author{
Gerhard H. Scholz and Holger Fleischmann
}

\begin{abstract}
The combination of basal insulin and glucagon-like protein 1 receptor agonists (GLP-1 RAs) is a new intriguing therapeutic option for patients with type 2 diabetes. In our daily practice we abbreviate this therapeutic concept with the term BIT (basal insulin combined incretin mimetic therapy) in a certain analogy to BOT (basal insulin supported oral therapy). In most cases BIT is indeed an extension of BOT, if fasting, prandial or postprandial blood glucose values have not reached the target range. In our paper we discuss special features of combinations of short- or prandial-acting and long- or continuous-acting GLP1 RAs like exenatide, lixisenatide and liraglutide with basal insulin in relation to different glycemic targets. Overall it seems appropriate to use a short-acting GLP-1 RA if, after the near normalization of fasting blood glucose with BOT, the prandial or postprandial values are elevated. A long-acting GLP-1 RA might well be given, if fasting blood glucose values are the problem. Based on pathophysiological findings, recent clinical studies and our experience with BIT and BOT as well as BOTplus we developed chart-supported algorithms for decision making, including features and conditions of patients. The development of these practical tools was guided by the need for a more individualized antidiabetic therapy and the availability of the new BIT principle.
\end{abstract}

Keywords: basal insulin, decision making, exenatide, glucagon-like protein 1 receptor agonist, individualized therapy, liraglutide, lixisenatide, type 2 diabetes mellitus

\section{Introduction}

The basal insulin combined therapy with incretin mimetic glucagon-like protein 1 receptor agonists (GLP-1 RAs), for which we use and would like to suggest the abbreviated term BIT, is a novel therapeutic strategy. It was introduced in clinical practice after its first regulatory approval in late 2011 and early 2012. BIT extends the concept of the basal insulin supported oral antidiabetic (OAD) therapy (BOT), which, during the last 10 years, has achieved acceptance as a basic therapeutic principle in the treatment of type 2 diabetes mellitus (T2DM). The combination of basal insulin with GLP-1 RAs adds some novel effects of pharmacological equivalents of GLP-1 to the approved positive actions of basal insulin. The new therapeutic principle has recently received considerable attention [Nauck and Meier, 2011; Barnett, 2012; Balena et al. 2013; Cohen et al. 2013; Gallwitz, 2013; Holst and Vilsbøll, 2013; Brown et al. 2013; Reid, 2013; Vora, 2013; Ahrén, 2014; Tibaldi, 2014].

Therapy with GLP-1 RAs was introduced in clinical practice in 2005. At this time the limited effects and the failure of a monotherapy with OADs became more and more clear [Kahn et al. 2006]. The combination of different types of these medications and even the dipeptidyl peptidase 4 (DPP-4) inhibitors showed their limits in comparison with GLP-1 RAs. This was especially true for the recovery and preservation of endogenous
Ther Adv Endocrinol

Metab

2014, Vol. 5(5) 95-123

DOI: 10.1177/

2042018814556099

(c) The Author(s), 2014. Reprints and permissions: http://www.sagepub.co.uk/ journalsPermissions.nav
Correspondence to: Gerhard H. Scholz, MD St. ElisabethKrankenhaus Leipzig, Biedermannstrasse 84 Leipzig, D-04277, Germany gerhard.scholza onlinehome.de Holger Fleischmann PhD Sanofi-Aventis Dt. GmbH, Berlin, Germany 
insulin production and secretion, glucagon suppression and weight reduction [Brunton, 2014]. Therefore the idea, starting with studies of synthetic c-terminal amidated GLP-1 from Creutzfeld's group in Germany [Schmidt et al. 1985], that GLP-1 RAs could support the production of insulin was fascinating. With the detection of exendin 4 (exenatide) and its insulin secretion stimulating properties [Eng and Eng, 1992; Göke et al. 1993] the development of new GLP-1 RAs has continued, leading to other clinically approved or investigated substances like (in alphabetical order): albiglutide, dulaglutide, liraglutide, lixisenatide, semaglutide and taspoglutide. Because the GLP-1 RA response depends on a more or less functioning $\beta$ cell as well as on hepatic and peripheral insulin resistance, preferred use of a combination with OAD medication was suggested, and for some, regulatory approval was achieved.

In clinical practice we observed that the effect of GLP-1 RAs in combination with OAD medication is unfortunately limited to a certain number of patients who reach near normoglycemia or show improvements in their weight or have a reduction in their blood pressure without adverse reactions. These limitations in the use of GLP-1 RAs in comparison to native GLP-1, which is able to normalize blood glucose without nausea and vomiting, were recently discussed [Nauck, 2013]. According to these authors, subcutaneous modifications of GLP-1 RAs or the application in subcutaneous tissue, irrigating subcutaneous nerves, which mediate gastrointestinal events, might be responsible for the differences in efficacy and side effects between GLP-1 and GLP-1 RAs.

Additionally GLP-1 RAs have different pharmacokinetic and pharmacodynamic properties and different effects regarding $\beta$-cell stimulation and inhibition of glucagon secretion, gastric emptying and satiety. The background of the resulting heterogeneity of the GLP-1 RA responses in clinical practice is unclear at present. Furthermore these responses probably consist of two components: the heterogeneity of different drug features and the heterogeneity of our patients. Regarding the latter, the pathophysiological heterogeneity in patients with T2DM, already present in the prediabetic state with impaired fasting glucose or impaired glucose tolerance (IGT) or both [Kanat et al. 2012], is in principal a matter of distinct defects in $\beta$-cell function and the degree of insulin resistance in the liver and skeletal muscle.
In contrast to the missing individualized concepts in the use of GLP-1 RAs in combination with an OAD or with insulin, there is a clear definition of the principles and the individual use of basal insulin in the basal insulin supported oral therapy called BOT. The early start of basal insulinization especially with longer-acting basal insulin seems more and more appropriate according to experimental data, for example, regeneration of the first phase and improvement of the second phase of insulin secretion [Pennartz et al. 2011], pooled analysis of prospective randomized clinical trials [Fonseca et al. 2011], observational trials, for example, EARLY [Hanefeld et al. 2012, 2014], a recently published open-label, randomized, prospective trial comparing the effects of insulin glargine versus metformin [Pistrosch et al. 2013], and the large and long-term randomized controlled trial (RCT) ORIGIN [Hanefeld et al. 2010; Gerstein et al. 2012]. The concept of early insulinization with basal insulin (after metformin therapy is initiated or if metformin is contraindicated) is also supported by Saxonian [Fachkommission Diabetes Sachsen, 2009; Rothe et al., 2010] and German national guidelines [Nationale Versorgungsleitlinie Diabetes, 2014], international position statements [Inzucchi et al. 2012] and clinical practice. One of the main clinical targets of basal insulin therapy is the normalization of fasting blood glucose. On this background there should be a complete or at least a partial reconstitution of the first-phase insulin secretion as well as the optimization of the second phase. As mentioned above, recent studies have shown that treatment with insulin glargine can partially reverse both phases of insulin secretion, an effect even more pronounced when fasting normoglycemia is achieved by intravenous insulin infusion [Pennartz et al. 2011].

Additionally, in case of a further progression of $\beta$ cell failure (irreversible loss of first-phase and probably second-phase insulin secretion) with enhanced postprandial glucose values, basal insulin treatment is regarded a substitutive therapy. In patients with optimized fasting blood glucose values after BOT but with inadequate average glycemia [hemoglobin A1c (HbAlc) above target], it can be assumed that the postprandial glucose values are elevated. Even if fasting plasma glucose (FPG) was best controlled for years as demonstrated in the ORIGIN trial with insulin glargine [median FPG $<5.3 \mathrm{mmol} / \mathrm{liter}(<95 \mathrm{mg} / \mathrm{dl})$ ], HbAlc has the tendency to increase slowly over time, obviously because complete control of 
postprandial values was not achieved [Gerstein et al. 2012]. To reduce postprandial glucose, a variety of therapeutic options exist, which have to be adapted to the special conditions of the patient.

In general, individualization of antidiabetic therapy, a major aspect and demand of nearly all new international guidelines, position statements or recommendations on diabetes treatment, should theoretically be based on a strategic concept. This concept should include individually weighted targets (near normoglycemia versus near normal blood pressure versus lipid reduction versus weight reduction versus costs versus side effects). It should be based on the analysis of a family history of early atherosclerosis and genetically determined risk factors, individual psychosocial aspects, social environment and of course the individual pathophysiological background including all components of the metabolic syndrome [Hanefeld and Leonhardt, 1981], or as we recently suggested, the Metabolic Vascular Syndrome (MVS) [Fachkommission Diabetes Sachsen 2007, 2013; Scholz, 2010].

The definition of individual targets is possible despite being a complicated task in practice. With regard to near normoglycemia or less well controlled diabetes, the aims depend on some of the patients' life circumstances (age, self confidence, life expectancy, duration of diabetes, compliance, comorbidities, support etc.) according to new national guidelines [NationaleVersorgungsleitlinie Diabetes, 2014] and international position and consensus statements of the American Diabetes Association (ADA) and the European Association for the Study of Diabetes (EASD) [Inzucchi et al. 2012], the American Association of Clinical Endocrinologists [Garber et al. 2013] and the periodically (at the beginning of the year) published practice recommendations of the ADA [American Diabetes Association, 2014].

According to our experience there is an unmet need for practical guidance on how to use the different GLP-1 RAs in combination with other antidiabetic medications. This seems especially true for the combination of basal insulin with GLP-1 RAs (BIT) as a possible extension of $\mathrm{BOT}$, if prandial or postprandial blood glucose values are out of target range.

In this paper we suggest simplified guidance on the basis of reviewing studies and our own experience of how the different types of GLP-1 RAs and basal insulin may fit in a unifying concept of determining treatment targets, integrating the knowledge of the heterogeneity of patients with T2DM and antidiabetic drugs. Additionally we provide a chart-supported guide for differential therapy using BOTplus or BIT if BOT has failed to achieve treatment targets, and we discuss their pros and cons.

\section{Pathophysiological background}

GLP-1 RAs are able to enhance or even to normalize the so-called 'incretin-effect' in relation to a meal-induced glucose transfer from the intestine to the blood in T2DM. Other metabolic effects of GLP-1 or GLP-1 RAs, not directly related to insulin secretion, are delayed gastric emptying and enhanced satiety, as well as the suppression of glucagon and its effects on liver gluconeogenesis during meals.

Although most of these effects are seen in the prandial or early postprandial situation, early night or fasting dysglycemia can be improved only by GLP-1 RAs but not through endogenous GLP-1 under normal conditions. The reasons for this are the special features of GLP-1 RAs in comparison with native GLP-1, longer half life and durable higher concentrations.

\section{Differentiation of GLP-1 RAs}

In principle, all GLP-1 RAs activate the GLP-1 receptor on $\beta$ cells. But the resulting insulin secretion during a mixed meal is not only related to the action of GLP-1 RAs on $\beta$ cells. Delayed gastric emptying, enhanced satiety related to gastric and cerebral signals as well as the suppression of glucagon and its effects on liver gluconeogenesis are also influenced by GLP-1 RAs at considerably different magnitudes. The clinical relevance of these differences is in discussion. Some of the possible relevant effects are summarized as follows.

Effects of GLP-1 RAs on first- and second-phase insulin secretion. One of the first most important events during the development of T2DM is the loss of the first phase of insulin secretion [Pratley and Weyer, 2001; Del Prato, 2003]. Different tests are available to prove the functional integrity of $\beta$-cells in this regard. For intravenous glucose a restoration of the first-phase insulin secretion was shown for exenatide [Fehse et al. 2005], liraglutide [Degn et al. 2004] and lixisenatide [Becker et al. 2014] (Figure 1) in patients pretreated with 


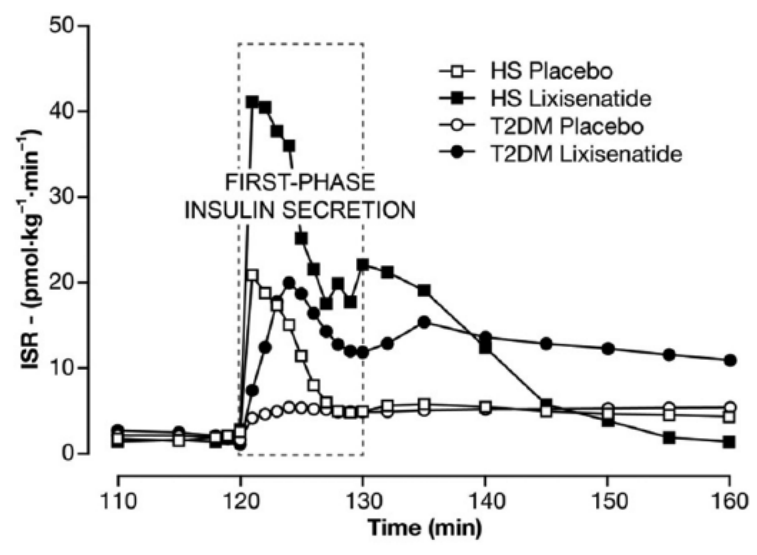

Figure 1. Time course of insulin secretion rate (ISR) of the first-phase insulin release after subcutaneous injection of lixisenatide at 0 min and after an intravenous glucose load at $120 \mathrm{~min}$ in healthy subjects (HS) and patients with T2DM treated with placebo versus lixisenatide [Becker et al. 2014].

diet and exercise or metformin and sulfonylurea (SU) in patients with moderate obesity with a relatively short duration of diabetes $(<5$ years) and good $(\mathrm{HbAlc}<7 \%)$ to moderate (HbAlc about $8 \%$ ) glycemic control.

Effect of GLP-1 RAs on gastric emptying. When estimating the stimulatory action of GLP-1 RAs on insulin secretion one has to take into account a second GLP-1 effect, retardation of gastric emptying which is different in the various GLP-1 RAs [Fineman et al. 2012]. The main results of a slower pass of the meal from the stomach to the intestine are a lowered flow of carbohydrates to the intestine and a decrease in postprandial glucose peaks and excursions. About $35 \%$ of the variance in glycemic response to oral glucose in patients with T2DM is due to gastric emptying [Jones et al. 1996]. Gastric emptying is influenced by a variety of individual factors, including longterm glycemic control, and is at least partially involved in the gastrointestinal symptom complexes of many patients with diabetes [Koch and Uwaifo, 2008].

Nevertheless the incretin effect to stimulate insulin secretion could be less pronounced if there is a stronger effect of GLP-1 RAs on gastric emptying. In comparison to continuous-acting GLP-1 RAs [exenatide long-acting release (LAR)] only the short-acting GLP-1 RAs (exenatide twice daily) have an insulin-sparing effect during a mixed meal [Degn et al. 2004]. The differences of short- and continuous-acting GLP-1 RAs in the insulin-sparing effect cannot be explained by different plasma concentrations, for example, in case of exenatide twice daily and exenatide LAR because during the test meal period the concentrations of exenatide were higher in exenatide LAR compared with exenatide twice daily [Fineman et al. 2012]. Because both medications contain the same substance this suggests that the kind of preparation in the case of exenatide determines the insulin-sparing effect.

The continuous-acting liraglutide (1.2 and 1.8 $\mathrm{mg} /$ day) has a moderate effect on gastric emptying during the early phase after a breakfast meal in patients with T2DM. But most of its prandial glucose-lowering effect is related to enhanced insulin secretion [Flint et al. 2011].

Also lixisenatide, a short-acting GLP-1 RA, retards gastric emptying [Lorenz et al. 2013]. The retardation of gastric emptying is so effective that much less insulin is necessary to lower the prandial glucose to an even greater extent after a standard meal compared with liraglutide [Kapitza et al. 2013]. The calculated effect of GLP-1 RAs on insulin secretion therefore has to be adjusted not only to the absolute amount of loaded glucose but also to the retardation of glucose absorption. This means that the measured insulin secretion rate after the application of a GLP-1 RA might be lower than on another GLP-1 RA but sufficient to meet the respective patient needs [Ratner et al. 2009].

Effects of GLP-1 RAs on glucagon. For more than 40 years the 'paradoxical' response of glucagon after carbohydrate or protein ingestion is known for patients with diabetes type 1 (T1DM) and T2DM [Unger et al. 1970; Müller et al. 1970]. In healthy individuals a carbohydrate meal suppresses glucagon secretion, whereas a protein meal enhances glucagon secretion. Hyperglycemia artificially induced in healthy individuals leads to a suppression of the glucagon-stimulating effect of protein. In patients with T1DM and T2DM, the glucagon concentration in the fasted state is already too high compared with the elevated blood sugar, so there is a fasting hyperglucagonemia. Additionally the normal suppressive effect of a carbohydrate meal is diminished or even a 'paradoxical' rise of glucagon can be observed in some individuals with diabetes. The protein-stimulated glucagon secretion is 'retained' but inappropriately high in relation to the prandial and postprandial hyperglycemia compared 
with healthy individuals under artificial hyperglycemic conditions. In summary, fasting hyperglucagonemia and prandial/postprandial 'paradoxically' elevated glucagon secretion both considerably contribute to the hyperglycemic state in T2DM [Shah et al. 2000]. Recently it was demonstrated that already in prediabetic states the normal pulsatile insulin-glucagon crosstalk (in simple terms, insulin high-glucagon low and vice versa) was lost [Rohrer et al. 2012]. According to new data there is a very early inhibitory effect of glucose on insulin but not on glucagon secretion, measurable in vitro $60-90 \mathrm{~s}$ after glucose increased. This early effect seems to be responsible for the physiological phase shift in the oscillatory secretion of insulin and glucagon and its disturbance might be the starting point for the crosstalk failure and the development of a diabetic state [Hellman and Grapengiesser, 2014].

GLP-1 RAs are effective means to reduce fasting and prandial/postprandial glucagon. Acute exenatide application diminished the mixed meal related increase in glucagon in T2DM [DeFronzo et al. 2008], explaining about one-third of the reduction in postprandial hyperglycemia [Cervera et al. 2008]. During longer-term exposure to exenatide (30 weeks) fasting glucagon was reduced significantly more with exenatide LAR compared with exenatide twice daily [Drucker et al. 2008]. However, exenatide twice daily had greater glucagon suppressive effect compared with the DDP-4 inhibitor sitagliptin when exenatide is given before breakfast and dinner [Berg et al. 2011].

At least in healthy individuals, exenatide does not suppress the glucagon release during exercise, preventing hypoglycemia during physical activity [Khoo et al. 2010]. Exenatide also suppresses glucagon in T1DM with and without residual insulin secretion [Ghazi et al. 2014].

For liraglutide a numerical but not significant difference in glucagon concentrations before and during a mixed meal was found in overweight Japanese patients with diabetes treated with liraglutide at a maximum dose of $0.9 \mathrm{mg} /$ day [Matsumoto et al. 2013]. The incremental ratio of glucagon was significantly reduced during the early phase of meal ingestion (15-60 min after the start of the meal), leading to the conclusion that glucagon suppression at least in this early phase of meal ingestion contributes to the postprandial glucose-lowering effect of liraglutide.
Lixisenatide given in the morning before a standard meal in comparison to placebo reduced $2 \mathrm{~h}$ glucagon as well as $2 \mathrm{~h}$ glucose and $2 \mathrm{~h}$ insulin significantly in a meta-analysis of RCTs [Ahrén et al. 2014a] and in further studies [Rosenstock et al. 2014b]. Interestingly there was a trend for a stronger correlation between the (reduced) $2 \mathrm{~h}$ postprandial glucagon and the (reduced) $2 \mathrm{~h}$ postprandial plasma glucose (PPG) with lixisenatide than with placebo.

There are several possible explanations for the effect of GLP-1 RAs on glucagon. It may directly bind to GLP-1 receptors on pancreatic $\alpha$-cells, although there are contradictory results about the presence and distribution of GLP-1 receptors in $\alpha$-cell populations [Moens et al. 1996; Heller et al. 1997]. Recently it was shown in a new transgenic mouse model that only about $10 \%$ of pancreatic $\alpha$-cells express GLP- 1 receptors, whereas they are much more abundant in $\beta$ - and in $\delta$-cells [Richards et al. 2014]. These findings support the concept that the glucagon-suppressive effect of GLP-1 and GLP-1 RAs is mediated through somatostatin, released by $\delta$-cells stimulated by GLP-1 RAs [de Heer et al. 2008].

Effects of GLP-1 RAs on fasting, prandial and postprandial glycemia. The different mode of actions of the various GLP-1 RAs and their formulations should have influence on their antihyperglycemic effects.

Indeed, differences between fasting and postprandial glycemia under the same GLP-1 RA substance exenatide but given twice a day or once weekly (LAR formulation) were shown [Drucker et al. 2008]. Although both exenatide formulations reduced fasting, prandial and postprandial glucose values, exenatide twice daily was superior in lowering glucose values after breakfast and dinner. On the contrary, exenatide LAR was superior in reducing fasting glycemia and $\mathrm{HbAlc}$ and more patients achieved $\mathrm{HbA} 1 \mathrm{c}$ below $7 \%$.

In another RCT comparing liraglutide with exenatide twice daily a predominant effect of liraglutide on fasting blood glucose and $\mathrm{HbAlc}$ was seen and in a higher number of patients a target $\mathrm{HbA} 1 \mathrm{c}$ below $7 \%$ was achieved [Buse et al. 2009], whereas exenatide twice daily was more effective after breakfast and dinner again.

Also lixisenatide has an inherent pronounced effect on the reduction of postprandial blood glucose with once-daily administration, especially at 
Table 1. Comparison of short-acting versus long-acting GLP-1 RAs [Meier et al. 2012] (reproduced with permission of the Nature Publishing Group).

\begin{tabular}{|c|c|c|}
\hline Parameters & $\begin{array}{l}\text { Short-acting GLP-1 receptor } \\
\text { agonists }\end{array}$ & $\begin{array}{l}\text { Long-acting GLP-1 receptor } \\
\text { agonists }\end{array}$ \\
\hline \multirow[t]{4}{*}{ Compounds } & Exenatide & Albiglutide \\
\hline & Lixisenatide & Dulaglutide \\
\hline & & Exenatide LAR \\
\hline & & Liraglutide \\
\hline Half life & $2-5 h$ & 12 h-several days \\
\hline \multicolumn{3}{|l|}{ Effects } \\
\hline Fasting blood glucose levels & Modest reduction & Strong reduction \\
\hline Postprandial hyperglycaemia & Strong reduction & Modest reduction \\
\hline Fasting insulin secretion & Modest stimulation & Strong stimulation \\
\hline Postprandial insulin secretion & Reduction & Modest stimulation \\
\hline Glucagon secretion & Reduction & Reduction \\
\hline Gastric emptying rate & Deceleration & No effect \\
\hline Blood pressure & Reduction & Reduction \\
\hline Heart rate & No effect or small increase (0-2 bpm) & Moderate increase (2-5 bpm) \\
\hline Body weight reduction & $1-5 \mathrm{~kg}$ & $2-5 \mathrm{~kg}$ \\
\hline Induction of nausea & $\begin{array}{l}20-50 \% \text {, attenuates slowly (weeks to } \\
\text { many months) }\end{array}$ & $\begin{array}{l}20-40 \% \text {, attenuates quickly }(\sim 4-8 \\
\text { weeks) }\end{array}$ \\
\hline
\end{tabular}

breakfast and partially at lunch as known from exenatide twice daily. In an earlier study lixisenatide lowered blood glucose after breakfast to near $100 \mathrm{mg} / \mathrm{dl}$ (5.6 mmol/liter) [Distiller and Ruus, 2008]. It was also sufficient in relation to other meals compared with placebo. This pronounced reduction of the prandial glucose values after a meal was also visible in relation to the continuous-acting GLP-1 RA liraglutide [Kapitza et al. 2013]. Additionally this study shows that, compared with the first day of treatment (acute response), the effect of lixisenatide on prandial glucose excursions on a standard meal after a longer treatment period is even better.

The different pharmacodynamic properties of GLP-1 RAs were the basis of a differentiation of so-called 'short-acting' GLP-1 RAs such as exenatide twice daily or lixisenatide, and 'continuous-acting' or 'long-acting' GLP-1 RAs such as exenatide LAR or liraglutide [Fineman et al. 2012; Meier, 2012; Vidal, 2013]. With albiglutide given once a week [Matthews et al. 2008], recently approved in the US by the Food and Drug Administration [FDA, 2014] with a positive opinion for Europe by the European Medicines Agency (EMA) [EMA, 2014a] and with the investigational drug dulaglutide [Jimenez-Solem et al. 2010] also given once a week, the group of continuous-acting GLP-1 RAs was recently extended. Albiglutide [Ahrén et al. 2014b; Woodward and Anderson, 2014] and dulaglutide [Umpierrez et al. 2014; Nauck et al. 2014] were found to preferentially suppress fasting glucose with improvement in overall glycemia. Compared with liraglutide the HbAlc reduction of albiglutide was lower with more injection site reactions but less gastrointestinal side effects [Pratley et al. 2014]. In contrast, in patients treated with maximum tolerated doses of metformin and pioglitazone, dulaglutide $0.75 \mathrm{mg} /$ day and $1.5 \mathrm{mg} /$ day compared with the short-acting exenatide twice a day was more effective in lowering $\mathrm{HbA} 1 \mathrm{c}$ with more patients achieving HbAlc below $7 \%$ and $6.5 \%$ with a similar or even lower risk of hypoglycemia [Wysham et al. 2014].

\section{Substance-dependent benefits of GLP-1 RA-} based strategies

In a recent review features and properties of GLP-1 RAs and their effects on fasting and postprandial glucose levels, insulin and glucagon secretion, gastric-emptying rate, blood pressure, heart rate, body weight reduction and main side effects were summarized (Table 1). This schematic representation can be used basically as a guide for the differentiated treatment 
with incretin-based therapeutics, including lixisenatide as a prandial and short-acting GLP-1 RA.

With respect to the application of GLP-1 RAs in the context of individualized T2DM therapy, the four main effects mentioned above are conceivable in many ways. As recently shown [Meier, 2013] the lowering of postprandial glucose with lixisenatide is possibly independent from $\beta$-cell function. In contrast, in the case of liraglutide, better $\mathrm{HbAlc}$ lowering was seen in patients with T2DM with retained $\beta$-cell function [Meier et al. 2011; Kozawa et al. 2012]. Using glucagon-stimulated c-peptide indices, a better response to liraglutide was seen in patients who had a better c-peptide response [Kondo et al. 2013]. During exenatide therapy the increase in postprandial glucose values was minimized even at a lower insulin secretion rate [Linnebjerg et al. 2008]. In agreement with these observations, the $\mathrm{HbAlc}$ glucose-lowering effect of exenatide twice daily was independent of diabetes duration up to more than 15 years after diabetes diagnosis [Rosenstock et al. 2012].

Additionally as a lower $\beta$-cell function often occurs in older patients with diabetes, the use of prandial active GLP-1 RAs such as lixisenatide or exenatide can be postulated to be advantageous for these stages of diabetes.

These and other clinical benefits of the different GLP-1 RAs are summarized in a recent critical analysis [Nauck et al. 2013].

In addition to the glucose-lowering effects of GLP-1 RAs discussed above, great benefits were seen, for example, avoidance of hypoglycemia because there is no insulin stimulation at low glucose levels, no risk of weight gain and a reduction of systolic blood pressure.

As already indicated, the different effects of GLP-1 RAs on reducing fasting and postprandial glucose even in the same patient are not only substance or structure related; they also depend obviously on other features, for example, on dose, time, sequence of substance application and drug formulation. The benefits of a GLP-1 RA therapy for individual patients in addition to their efficacy were summarized to be safety and easy manageability, without complex dosing or monitoring algorithms [Gallwitz, 2013].

\section{Practical considerations}

How can this knowledge be used for an individual therapeutic regime?

According to the new guidelines for patients with T2DM, specific features of patients, their abilities, preferences and living and surrounding conditions have to be included in decision making. However, there are formal criteria, included in the drug information sheet, limiting the use of different medications under certain circumstances.

Unfortunately the long-acting exenatide LAR can only be combined with OADs but not with insulin, although it could be a very interesting therapeutic option.

\section{Practical approach in the use of GLP-1 RAs}

In addition to the indications, comorbid conditions which might influence the use of GLP-1 RAs in general also have to be considered (Figure 2). Although they should play a role in the decisionmaking process, many of them were not studied thoroughly or were part of the exclusion criteria in clinical studies.

GLP-1 RAs can have a positive influence on existing comorbid conditions or even preventive effects on possible future complications, which should be considered.

Bearing in mind the situation for many antidiabetic medications, a German diabetes expert group has recently released a proposal for decision making to overcome this problem in the general use of antidiabetic medications for the first-line treatment of patients with T2DM [Tschöpe et al. 2013]. In addition to our own experience in the use of these medications in firstand second-line treatments and especially in BIT, we have taken into account the opinion of these experts in the selection and ranking of the conditions in Figures 2 and 4 and in the following.

First, obesity. Especially android obesity with visceral fat accumulation and nonalcoholic fatty liver disease (NAFLD) is a principal target in T2DM. This special kind of fat distribution is associated with insulin resistance, enhanced gluconeogenesis, hypertension, lipid dysregulation, inflammation, risk of thrombosis and many other risk factors for cardiovascular events [Lee et al. 2013]. Interestingly, the GLP-1 response to oral glucose is reduced in NAFLD and nonalcoholic 


\section{Comorbid conditions which may affect the use of GLP-1RA}

\begin{tabular}{|c|c|}
\hline $\begin{array}{l}\text { Obesity }\left(\mathrm{BMI} \geq 30 \mathrm{~kg} / \mathrm{m}^{2}\right) \\
\text { Preferred, if of android origin with visceral/liver fat accumulation } \\
\text { Reduction in liver fat correlated with improvement in } \mathrm{HbA} 1 \mathrm{c}\end{array}$ & \\
\hline $\begin{array}{c}\text { Enhanced risk of hypoglycemia } \\
\text { (older age, renal failure, medication) or } \\
\text { need to avoid hypoglycemia (e.g. professional reasons) } \\
\end{array}$ & \\
\hline $\begin{array}{c}\text { Age } \\
\begin{array}{c}\text { No use below } 18 \text { years, in older patients preferred use in 'young old' (65-79 years), } \\
\text { no data in 'old old' (80-89 years) and older }\end{array}\end{array}$ & \\
\hline $\begin{array}{c}\text { Previous macro- and microvascular diseases } \\
\text { Until now, no additional risks observed, protective effects possible, } \\
\text { Caution: preexisting maculopathy, higher grade retinopathy, longer diabetes duration }\end{array}$ & \\
\hline $\begin{array}{c}\text { Renal failure } \\
\text { Use with care (lixisenatide: } \mathrm{CrCl}<50 \geq 30 \mathrm{ml} / \mathrm{min} \text { ), dose reduction (exenatide: } \mathrm{CrCl} \\
<60 \geq 30 \mathrm{ml} / \mathrm{min} \text { ), not suggested (liraglutide: } \mathrm{CrCl}<60 \mathrm{ml} / \mathrm{min} \text {, exenatide and } \\
\text { lixisenatide: } \mathrm{CrCl}<30 \mathrm{ml} / \mathrm{min} \text { ). }\end{array}$ & \\
\hline $\begin{array}{l}\text { Liver disease } \\
\text { Exenatide/lixisenatide: side effects not expected but no conclusive information, } \\
\text { liraglutide: not suggested in mild, severe and very severe liver failure }\end{array}$ & \\
\hline $\begin{array}{c}\text { Gastrointestinal and pancreatic diseases } \\
\text { Exenatide, liraglutide and lixisenatide are not recommended in patients with severe } \\
\text { gastrointestinal diseases and contraindicated in patients with previous pancreatitis } \\
\text { and pancreas carcinoma }\end{array}$ & \\
\hline
\end{tabular}

Figure 2. Comorbid conditions which may affect the use of GLP-1 RAs. BMI, body mass index; $\mathrm{CrCl}$, creatinine clearance; GLP-1 RA, glucagon-like protein 1 receptor agonist; HbA1c, hemoglobin A1c.

Algorithm for optimizing BOT with short acting GLP-1 RA

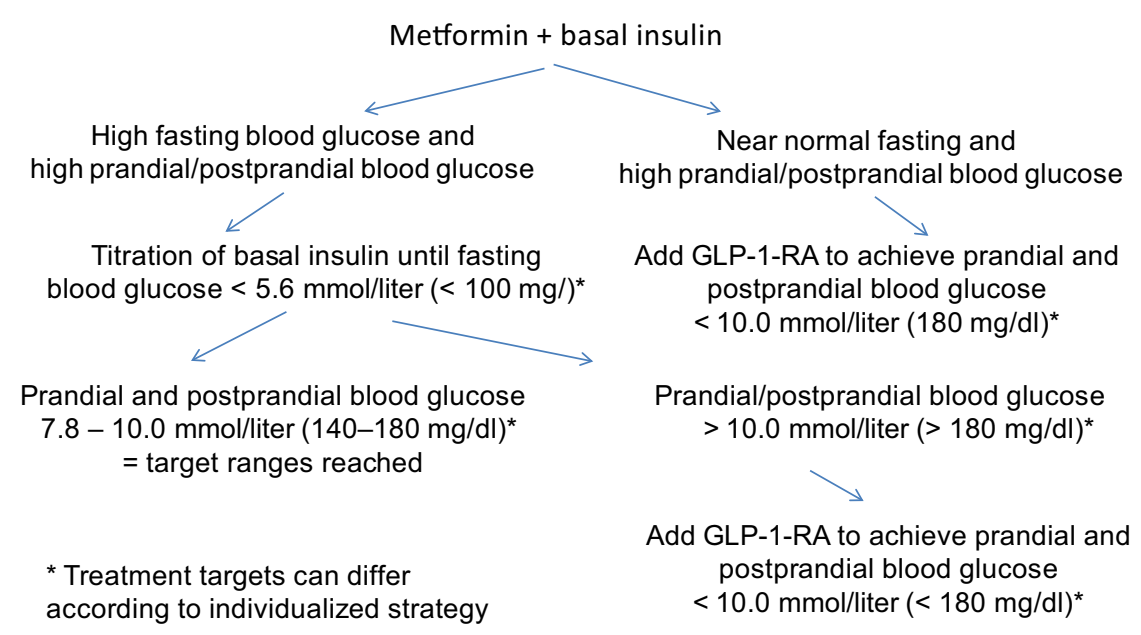

Figure 3. Algorithm for optimizing basal insulin supported oral therapy (BOT) with short-acting glucagon-like protein 1 receptor agonists (GLP-1 RAs).

steatohepatitis in patients with insulin resistance, hyperinsulinemia and hyperglucagonemia but (still) without diabetes, one possible argument for the use of GLP-1 RAs under these conditions [Bernsmeier et al. 2014].
Indeed GLP-1 RA therapy reduced not only weight but more specifically also abdominal/visceral and liver fat and several biomarkers related to inflammation and insulin resistance [Tushuizen et al. 2006; Buse et al. 2007; Bunck et al. 2010; 
Inoue et al. 2011; Cuthbertson et al. 2012; Shao et al. 2014] and, in initial studies, improved liver histology in patients with diabetes and NAFLD [Kenny et al. 2010]. Therefore, it makes sense to put this type of obesity in the first row of our table.

In a recent review about the effects of GLP-1 RAs on body weight in patients with diabetes [Vilsbøll et al. 2012], including randomized trials published between 2004 and 2011, groups of GLP-1 RA (exenatide given twice daily, exenatide given once weekly, as a long-acting release, and liraglutide given once daily) achieved a significantly greater weight loss than control groups (with different antidiabetic medication) of $-2.8 \mathrm{~kg}$ [ $95 \%$ confidence interval (CI) -3.4 to -2.3 ]. The weight reduction was seen for trials in which the control group received insulin $(-4.8 \mathrm{~kg}, 95 \% \mathrm{CI}-5.1$ to -4.5 ; six trials), OADs including metformin or SU compounds $(-3.0 \mathrm{~kg}, 95 \% \mathrm{CI}-4.9$ to -1.2 ; three trials) and DPP-4 inhibitors $(-2.0 \mathrm{~kg}$, $95 \% \mathrm{CI}-2.9$ to -1.1 ; two trials).

A prospective study [Cuthbertson et al. 2012] demonstrated that GLP-1 RA therapy (with exenatide or liraglutide) for 6 months in patients with obese T2DM treated with metformin and SU/DPP-4 inhibitors dramatically improved hepatic steatosis. Intrahepatic lipid content (IHL) measured by proton magnetic resonance spectroscopy has been reduced by $42 \%$. Patients with the highest pretreatment IHL had the greatest absolute reduction in IHL. Interestingly, the individual changes in IHL did not correlate with changes in total body weight, total abdominal fat, visceral adipose tissue or subcutaneous tissue, but it did correlate with reduction in $\mathrm{HbAlc}$.

The German diabetes expert group [Tschöpe et al. 2013] suggested using the following antidiabetic medication as second-line treatment in patients with metformin who fail to achieve treatment targets [fasting plasma glucose of 3.9-7.2 $\mathrm{mmol} / \mathrm{liter}$ $(70-130 \mathrm{mg} / \mathrm{dl})$ or postprandial plasma glucose below $10.0 \mathrm{mmol} /$ liter $(180 \mathrm{mg} / \mathrm{dl})]$ in order of weight benefit: GLP-1 RAs, DPP-4 inhibitors, acarbose, bile acid sequestrants and amylin analogs. In case of indicated insulin treatment the group suggested considering a basal insulin supplementation.

In summary, there are many good reasons to use GLP-1 RAs in obese patients with diabetes, especially when a high liver fat content (steatosis hepatis) is present, even as first-line drugs but normally after metformin or if metformin is contraindicated.

Second, risk of hypoglycemia. Many patients have conditions leading to increased risk of hypoglycemia when treated with SU and short-acting or mixed insulins. Other patients have occupations that exclude the ingestion of substances with hypoglycemic potential. In a recent meta-analysis, hypoglycemia with glucose up to $3.1 \mathrm{mmol} / \mathrm{liter}(\leqslant 56$ $\mathrm{mg} / \mathrm{dl})$ or up to $2.8 \mathrm{mmol} / \mathrm{liter}(\leqslant 50 \mathrm{mg} / \mathrm{dl})$ was experienced by $10.1 \%(95 \%$ CI $7.3-13.8 \%)$ and $5.9 \%$ (95\% CI $2.5-13.4 \%)$ and severe hypoglycemia by $0.8 \%$ (95\% CI $0.5-1.3 \%)$ of patients with any SU treatment, with the lowest risk for gliclazide [Schopman et al. 2014]. Although the risk of severe hypoglycemia seems to be low, the authors acknowledge that the real-world risk of hypoglycemia might be considerably higher compared with RCTs.

Hypoglycemia, including silent hypoglycemic episodes, have tremendous effects on cardiovascular morbidity and mortality [Hanefeld et al. 2013; Mellbin et al. 2013; Stahn et al. 2014] as well as on cerebral function [Feinkohl et al. 2014].

In a recent survey the main predictors of selfreported severe hypoglycemia (about $11 \%$ ) in multiethnic patients with T2DM age 30-80 years and treated with different antidiabetic medications were as follows: near normal (HbAlc $<6 \%$ ) and very poor glycemic control (HbAlc $>9 \%$ ) unrelated to the age of patients, duration of diabetes and use of insulin [Lipska et al. 2013]. These observations support the results of the ACCORD trial. Patients with Diabetes who failed to achieve a lower $\mathrm{HbA} 1 \mathrm{c}$ level despite intensive or standard diabetes treatment experienced high rates of severe hypoglycemia [Miller et al. 2010]. One of the most prevalent causes of hypoglycemia in this study was variation in food intake (about $50 \%$ of all events) [Bonds et al. 2012]. In another recent report, risk of having hypoglycemia was increased for renal failure, autonomic neuropathy, adrenocortical insufficiency and in patients with mental disorders, including dementia, depression, anxiety and affective disorders [Kostev et al. 2014]. According to their mode of action, GLP-1 RAs in monotherapy or added to metformin or glitazones do not enhance the risk of hypoglycemia [Fonseca, 2014].

\section{Third, age}

Many older patients have problems with complex kinds of antidiabetic therapies because of decline 
in cognitive function, loss of social support, erratic meals and coexisting chronic illnesses. In a consensus report of the ADA [Kirkman et al. 2012] a relaxation of $\mathrm{HbAlc}$ targets was suggested depending on comorbid conditions. For healthy patients (few coexisting chronic illnesses, intact cognitive and functional status with longer remaining live expectancy), HbAlc less than $7.5 \%$, fasting plasma glucose of $5.0-7.2 \mathrm{mmol} /$ liter $(90-130 \mathrm{mg} / \mathrm{dl})$ and bedtime plasma glucose of $5.0-8.3 \mathrm{mmol} /$ liter $(90-150 \mathrm{mg} / \mathrm{dl})$ is suggested. If the health status is more complex (multiple chronic illnesses or there are two or more impaired activities of daily living), the suggestion is $\mathrm{HbA} 1 \mathrm{c}$ less than $8 \%$, fasting plasma glucose of $5.0-8.3 \mathrm{mmol} / \mathrm{liter}(90-150 \mathrm{mg} / \mathrm{dl})$ and bedtime plasma glucose of $5.6-10.0 \mathrm{mmol} / \mathrm{liter}(100-180$ $\mathrm{mg} / \mathrm{dl}$ ). In very complex or poor health status (long-term care or end-stage chronic illnesses or moderate to severe cognitive impairment or two or more impaired activities of daily living), $\mathrm{HbA} 1 \mathrm{c}$ less than $8.5 \%$, fasting plasma glucose of 5.6-10.0 $\mathrm{mmol} / \mathrm{liter}(100-180 \mathrm{mg} / \mathrm{dl})$ and bedtime plasma glucose of $6.1-11.1 \mathrm{mmol} /$ liter $(110-200 \mathrm{mg} / \mathrm{dl}$ ) is sufficient. With these suggestions and the detrimental effects of hypoglycemia on older people in mind, there seems to be an indication for the use of GLP-1 RAs at least in the above-mentioned healthy patients and even in the more complex health stages, although randomized controlled BIT studies evaluating any potential benefit in older people are missing [Vora, 2013]. In retrospective observational studies there seems to be a certain preference for GLP-1 RA use in the 'young old' (65-79 years) compared with the 'old old' (80-89 years) with the notion that the 'oldold' had the same mean HbAlc values (about $7 \%$ ) with less antidiabetic medication [Thompson et al. 2013].

Because of missing, study-based evidence the above-mentioned German diabetes expert group generally suggested the preferred use of metformin, GLP-1 RAs and DPP-4 inhibitors and long-acting insulins over other treatment options (SU, glinides and glitazones) in older patients [Tschöpe et al. 2013].

Fourth, micro- and macrovascular diseases. Improvement of body weight, blood lipids, blood pressure and inflammatory markers, clearly documented effects of GLP-1 RAs, should all lead to a reduced risk of micro- and macrovascular events. Because the first randomized, long-term clinical trials with GLP-1 RAs and micro- and macrovascular events as end points are expected to finish in 2016 , only experimental data, retrospective data and results of short-term studies and meta-analyses are available. Positive metabolic and blood pressure effects in patients with diabetes were worked out in recently published original articles [Best et al. 2011; Lønborg et al. 2012; Nathanson et al. 2012], reviews [Mannucci and Dicembrini, 2012; Burgmaier et al. 2013] and in vitro and in vivo studies in animals supporting an indirect (mediated via improvement of glycemia) and a direct nonglucose-dependent protective effect of GLP-1 RAs on the cardiovascular system.

One randomized study in patients without diabetes with prior myocardial infarction and primary transcutaneous revascularization has shown that, in comparison with placebo, the GLP-1 RA exenatide is able to produce a small reduction in infarct size after reperfusion [Lønborg et al. 2012]. This effect was seen at a plasma concentration three times higher than the concentration achieved by the usually suggested subcutaneous dose. In patients with T2DM with heart failure an exenatide infusion improved cardiac index and decreased the pulmonary capillary wedge pressure without serious adverse events, despite an increase in heart rate and a higher blood pressure in few patients [Nathanson et al. 2012]. However, in a 6-month short-term trial with GLP-1 RAs in obese patients with T2DM no changes in brachial artery endothelial-dependent flow-mediated dilation and endothelial-independent glyceryl trinitrate function and carotid intima-medial thickness were found [Hopkins et al. 2013].

In a retrospective analysis of a large database of patients with diabetes treated with exenatide twice daily (about 40,000 patients) and other antidiabetic medications (about 400,000 patients), exenatide-treated patients were significantly less likely to have a cardiovascular disease (CVD) event as well as CVD-related and all cause-related hospitalizations than patients not treated with exenatide, although the exenatidetreated patients had more prior ischemic heart disease, obesity, hyperlipidemia, hypertension or other comorbidities at baseline [Best et al. 2011].

In meta-analyses of patients with T2DM with different antidiabetic medications, GLP-1 RAs in comparison with OADs and insulin reduced systolic and diastolic blood pressure and total cholesterol concentrations as well as other components 
of the metabolic vascular syndrome, with a small but significant enhancement of heart rate [Robinson et al. 2013; Monami et al. 2014a; Katout et al. 2014]. All GLP-1 RA meta-analyses regarding CVD actually have considerable limits because most finished and analyzed RCTs were not specifically designed to answer CVD questions. According to a recent sequential analysis based on RCTs until January 2013, the accumulated sample size for GLP-1 RAs versus placebo was only $11 \%$ (7445 of 65,212) and for GLP-1 RAs versus an active comparator it was only $13 \%$ $(10,157$ of 79,198$)$ of the required information size [Wu et al. 2014]. In order to gain clarity about cardiovascular benefits and risks of GLP-1 RAs, more long-term trials and population-based studies are required.

Diabetic retinopathy (DR), one of the most severe microvascular long-term complications of hyperglycemia, can temporarily or progressively be worse after initiation of a glucose-lowering therapy. A few years ago a dramatic case report about the development of a DR after initiation of exenatide was reported [Brooks and Lissett, 2009]. In a recent study with exenatide [Varadhan et al. 2011 ], 30\% $(n=49)$ of patients had a progression of DR, although $96 \%(n=47)$ had improvement in $\mathrm{HbA} 1 \mathrm{c}$.

A new developed maculopathy was documented in 15 patients without indication for laser therapy. With greater reduction of $\mathrm{HbAlc}$ the proportion of patients with progression of DR was higher. Also the degree of worsening of DR was proportionate to $\mathrm{HbA} 1 \mathrm{c}$ reduction.

In a follow-up study of 39 of these patients [Varadhan et al. 2014], 31 had an improvement or no documented change, although $\mathrm{HbA} 1 \mathrm{c}$ showed a rebound in 23 patients. Eight patients had progression of DR. Only two of these patients had a sustained reduction in $\mathrm{HbAlc}$. From the 15 patients with maculopathy, in 12 patients there was a regression without laser treatment and a stable status was seen in the other 3 patients. Of the 14 patients who had developed DR for the first time since the beginning of the GLP-1 RA therapy, 10 patients showed an improvement in DR on follow up and a further 3 remained stable.

The authors concluded that the deterioration in retinal function is transient and reversible during continuation of GLP-1 RA treatment. As possible risk factors for a persistent deterioration, they identified pre-existent maculopathy, higher grade of retinopathy and longer duration of diabetes.

In accordance with the German diabetes expert group [Tschöpe et al. 2013], although there are very limited data about the micro- and macrovascular effects of GLP-1 RAs from clinical trials, it seems appropriate to also include GLP-1 RAs in the therapeutic portfolio of patients with cardiovascular as well as cerebrovascular diseases.

Fifth, renal failure. GLP-1 RAs can be used in early stages of renal failure at different degrees according to their regulatory approval. In a recent review the difference in the elimination kinetics of GLP-1 RAs and their relationship with clinical outcomes at various stages of renal failure were analyzed [Filippatos and Elisaf, 2013]. Although exenatide is cleared by glomerular filtration, no dosage adjustment of exenatide is required for patients with mild to moderate renal impairment. However, the recommended starting dosage of $5 \mu \mathrm{g}$ exenatide may not be suitable for patients with end-stage renal disease or severe renal impairment [creatinine clearance $(\mathrm{CrCl})<30 \mathrm{ml} / \mathrm{min}$ ]. The exenatide dose should be based on renal function rather than age in older patients with T2DM.

In patients with T2DM with albuminuria, exenatide reduced urinary type IV collagen and $24 \mathrm{~h}$ urine albumin as well as transforming growth factor $B 1$ [Zhang et al. 2012]. Other renoprotective effects against increased renal oxidative stress under chronic hyperglycemia were recently shown in an experimental animal model [Fujita et al. 2014].

According to the regulatory approval, treatment in renal failure has to be done with care (lixisenatide: $\mathrm{CrCl}<50$ and $\geqslant 30 \mathrm{ml} / \mathrm{min}$ ), dose reduction (exenatide: $\mathrm{CrCl}<60$ and $\geqslant 30 \mathrm{ml} / \mathrm{min}$ ) or is not suggested (liraglutide: $\mathrm{CrCl}<60 \mathrm{ml} / \mathrm{min}$; exenatide and lixisenatide: $\mathrm{CrCl}<30 \mathrm{ml} / \mathrm{min}$ ).

In one case report a reversible pancreatitis/pancreatic tail swelling was seen in an older patient with end-stage renal disease on liraglutide [Nakata et al. 2012]. However, two cases of severe renal failure were reported in patients with diabetes receiving GLP-1 RAs [Dubois-Laforgue et al. 2013].

In a recent review about safety of GLP-1 RA use in renal failure [Giorda et al. 2014], the authors 
concluded that liraglutide has a slightly wider database than either exenatide or lixisenatide in favor of its use in patients with renal impairment. But the scant evidence does not allow more special conclusions or recommendations. The German diabetes expert group [Tschöpe et al. 2013] rated microalbuminuria (no firm recommendations) and renal failure as neutral (with low evidence) and generally suggested glitazones, glinides, insulin, and more recently DPP-4 inhibitors.

Sixth, hepatic failure. Data on GLP-1 RA therapy in patients with hepatic impairment in clinical studies are scarce. In the documents for the regulatory approval of exenatide it was stated that an increase in blood concentrations of exenatide is not expected because exenatide has been mainly renally excreted. For liraglutide, the use was not suggested in mild, moderate and severe liver failure and for lixisenatide the pharmacokinetics was not expected to be affected by liver disease. In a recent review about the safety of GLP-1 RAs in patients with hepatic impairment [Giorda et al. 2014], no clear conclusion could be drawn because of scarcity of information. Additional clinical trials are strongly suggested. The German diabetes expert group [Tschöpe et al. 2013] graded liver failure as being neutral (not recommended and not contraindicated, no conclusive recommendations) in relation to GLP-1 RA therapy. The group suggested, because of the possible hepatic side effects of all other antidiabetic medications, the use of insulin is the remaining option for glycemic control.

Seventh, pancreatic and gastrointestinal dysfunction. Based on some experimental, animal (mainly rodents) and human data, concerns were expressed that GLP-1 RA therapy might have detrimental effects on human pancreas and thyroid [Elashoff et al. 2011; Butler et al. 2013]. Some of the arguments have already at least partially been refuted [Drucker, 2013; Nauck, 2013]. Even if there is an increased risk for pancreatitis with incretin therapies, the risk should be limited to 1.5 times the diabetic population [Nauck and Meier, 2014].

Recent meta-analyses of patients treated with GLP-1 RAs have not shown an enhanced risk in the development of pancreatitis [Monami et al. 2014c; Li et al. 2014]. This view has been supported by a recently published joint statement of the EMA with the FDA [Egan et al. 2014].
Nevertheless, the use of GLP-1 RAs should be avoided in patients with previously or actually known pancreatitis or in patients with severe gastrointestinal symptoms or diseases and previous thyroid cancer or multiple endocrine neoplasia.

We should also avoid the use of any GLP-1 RAs in patients with a history of pancreas carcinoma, although the recently released statements of the EMA and the FDA actually found no evidence for an increased carcinoma risk. Nevertheless further long-term observation of side effects of GLP-1 RAs is reasonable and necessary regarding the usual time lag between drug exposure and clinical symptoms, especially in chronic or malignant diseases.

\section{Practical approach of BIT with liraglutide and insulin detemir or insulin degludec or any other basal insulin}

The use of longer-acting liraglutide is actually no longer limited to a combination with insulin detemir after a certain treatment period with liraglutide and OADs. Recently a positive opinion of the EMA [EMA, 2014b] adopted a new indication to include the combination of liraglutide with any basal insulin. The EMA additionally adopted a new indication to include the combination of the longer-acting insulin degludec with any GLP-1 receptor agonist [EMA, 2014c].These decisions will provide the basis for a more intense use of liraglutide and insulin degludec in the BIT concept at least in Europe but probably in the future also worldwide and in the USA, where glargine is the leading basal insulin [Turner et al. 2014]. The results of recent clinical studies in obese patients with T2DM using the combination of liraglutide and insulin degludec plus continued metformin but discontinuation of SU as a special kind of BIT were encouraging: favorable results for glycemia $(-0.5 \% \mathrm{HbA} 1 \mathrm{c})$, induction of a further slight weight loss after randomization, and no severe hypoglycemic events as well as very low rates of minor hypoglycemia and other side effects [DeVries et al. 2012]. In a recently published study comparing BIT (liraglutide added to insulin degludec and metformin) versus BOTplus (adding a single daily dose of insulin aspart to insulin degludec and metformin) in patients with T2DM with baseline HbAlc of $7.7 \%$, the BIT improved $\mathrm{HbAlc}(-0.74 \%)$, with $49 \%$ of patients achieving an $\mathrm{HbA} 1 \mathrm{c}$ less than $7 \%$ without weight gain and confirmed hypoglycemia [Mathieu et al. 2014]. If the new combination of insulin degludec and liraglutide (IDeg/Lira) is additionally approved 
in a fixed form by the EMA and the FDA, the concept of BIT will gain even more acceptance in clinical practice.

At the moment, if we have a patient who is obese, receiving liraglutide and metformin or SU but fasting and postprandial values cannot be kept in the target range, we gradually add insulin detemir in the evening (at high fasting glucose values) or morning (if prandial or postprandial glucose values are out of range) or twice daily if glucose targets with a once daily approach are not reached. At the beginning of combination therapy with liraglutide we stop the use of a SU to avoid the risk of hypoglycemia. According to the abovementioned new indications for insulin degludec and liraglutide [EMA, 2014b], it is advised that, when adding insulin degludec to GLP-1 receptor agonists, the recommended daily starting dose is 10 units followed by individual dosage adjustments.

When adding GLP-1 receptor agonists to insulin degludec, it is recommended that the dose of insulin degludec is reduced by $20 \%$ to minimize the risk of hypoglycemia. Subsequently, dosage should be adjusted individually.

In our daily practice with liraglutide and insulin detemir in combination therapy this kind of BIT is well tolerated and long lasting, and this should be true for the combination of liraglutide with insulin degludec as well. Nevertheless in the former combination we have observed some patients with low or, over time, reduced effects on body weight and glycemia. A few patients were switched to a BIT scheme with shorter-acting GLP-1 RAs with success, possibly because of their long lasting retardation effect on gastric emptying.

\section{Practical approach of BIT with exenatide or lixisenatide and basal insulin}

Because of the widespread use of the BOT regime with insulin glargine, it seems reasonable to simply extend this treatment option to BIT by adding prandial acting exenatide or lixisenatide, if postprandial glucose values exceed the treatment target. This kind of BIT will also gradually reduce fasting blood glucose values. In Figure 3 a treatment algorithm is suggested.

In accordance with this strategy, exenatide twice daily [Riddle et al. 2010; Buse et al. 2011; Tobin et al. 2012] as well as lixisenatide [Seino et al. 2012; Riddle et al. 2013a, 2013b] effectively lowered prandial/postprandial glucose values in patients on basal insulin, supporting the BIT concept.

Both prandial-acting GLP-1 RAs have nearly comparable effects on glucose profiles, average glycemia and number of patients achieving target $\mathrm{HbAlc}$ values according to a recently published study [Rosenstock et al. 2013], fulfilling noniferiority criteria for lixisenatide versus exenatide. In comparison to exenatide given twice daily, the patients with once daily applied lixisenatide had slightly lower weight loss but experienced a lower incidence of hypoglycemia and fewer gastrointestinal side effects.

So, if we have a patient with high prandial/postprandial blood glucose values, high body weight, but a tendency to some hypoglycemic events during BOT, a tendency for overall gastrointestinal discomfort and the wish for once daily injection (for the GLP-1 RA), we would surely prefer lixisenatide over exenatide.

If we have a more robust patient with obesity, and the main aims are to lower prandial/postprandial blood glucose and body weight (and liver fat), with possibly two or three 'main' meals, without hypoglycemic tendency who has never experienced gastrointestinal discomfort and has no problems with two injections (of GLP-1 RAs), we would probably try exenatide twice daily.

In practice we have also successfully switched between both kinds of BIT, for example, a patient on exenatide unexpectedly experienced a higher degree of gastrointestinal discomfort and was more fortunate with lixisenatide; and a patient on lixisenatide, who did not achieve sufficient control of late evening postprandial blood glucose, had better control with twice daily exenatide.

\section{Should we reduce the dose of basal insulin} during initiation of short-acting GLP-1 RAs?

Because it might be that adding a short-acting GLP-1 RA to continued BOT improves endogenous insulin secretion and reduces prandial and postprandial blood glucose, theoretically there is a certain risk of additional hypoglycemia at least at the beginning of BIT.

In our experience with more patients with hyperglycemia under hospital conditions, we found no real risk if we continued with the initial basal insulin dose in the case of insulin detemir and insulin glargine. This might be different in 
outpatient clinical settings, where the patient's daily activities are not under medical control and the patient already has hypoglycemia. So it seems advisable under these conditions to reduce the dose of the basal insulin, especially if high or very high doses were used, to avoid any kind of hypoglycemia. For insulin glargine an advisable titration could follow the standard regime approved in clinical studies, for example, in the case of fasting plasma glucose less than $4.0 \mathrm{mmol} /$ liter $(<72 \mathrm{mg} / \mathrm{dl})$ a reduction of 2 units per day is advised [Yki-Järvinen et al. 2007]. Regarding the new combination of insulin degludec with liraglutide according to the published positive summary of opinion of the EMA, if a GLP-1 RA is added to insulin degludec, the dose of insulin degludec should be reduced by $20 \%$ [EMA, 2014a].

\section{BOTplus versus BIT: postprandial hyperglycemia as treatment target}

Many studies have shown an importance of fasting, prandial and postprandial plasma glucose for the development of microvascular and macrovascular diseases.

Starting with the hypothesis that the loss of the first phase of insulin secretion in response to a meal challenge test leads to increasing postprandial hyperglycemia, even in recently diagnosed individuals [Coates et al. 1994; Pratley and Weyer, 2001; Del Prato, 2003], it seems reasonable that postprandial hyperglycemia is a key factor in T2DM. Many studies found, in addition, that increasing postprandial hyperglycemia is not only a major point in conversion from pathological glucose tolerance to early diabetes stages with near normal fasting blood glucose, but also in patients with near normal glycemic control and enhanced glucose excursions. Postprandial glycemia excursions make an even greater contribution to $\mathrm{HbAlc}$ values when the glycemic control improves in patients treated with antidiabetic medications [Monnier et al. 2003, 2007; Bonora et al. 2006].

Postprandial hyperglycemia is one of the most important problems from the beginning of the disease until later stages when normal glucose control is targeted. Some studies also confirmed that postprandial hyperglycemia is an independent cardiovascular risk factor whether or not these studies are based on $2 \mathrm{~h}$ glucose levels after oral glucose tolerance test or after meal challenge tests [Hanefeld et al. 2000; Balkau et al. 2004; Ceriello et al. 2004; Cavalot et al. 2006, 2011; Meier et al.
2009]. The obvious idea to prevent CVDs by lowering postprandial hyperglycemia was examined in the STOP-NIDDM trial and the reduction of incidence of new cardiovascular events in people with IGT has been shown [Chiasson et al. 2003]. According to the results of several outcome studies like ACCORD [Gerstein et al. 2008], VADT [Duckworth et al. 2009], ADVANCE [Patel et al. 2008] and HEART2D [Raz et al. 2009] in combination with the data of UKPDS [Turner et al. 1998; Stratton et al. 2000] and DCCT/EDIC [Nathan et al. 2005] and their long-term follow ups, the UKPDS 10-year post-trial monitoring [Holman et al. 2008] and the Epidemiology of Diabetes Interventions and Complications observational follow up [Nathan and DCCT/EDIC Research Group, 2014], it seems plausible that bearing the 'metabolic memory' [Nathan et al. 2005] and the 'glycemic thresholds' [Zoungas et al. 2012] for the association of HbAlc levels with vascular complications and death in mind, hyperglycemic control should start as early as possible to show a beneficial effect.

Lowering postprandial glycemia as part of the 'glycose triad' [Monnier et al. 2006; Ceriello, 2010] seems to be valuable and necessary, and according to the recently published International Diabetes Federation Guideline for Management of PostMeal Glucose in Diabetes is supported by a high level of evidence [International Diabetes Federation, 2011].

\section{BOTplus versus BIT: pros and cons}

In the following section of our paper we present available data from RCTs using BOTplus or BIT in patients with T2DM and in summary a graded chart (Figure 4) as support for an individualized decision-making process.

BOTplus. The addition of one bolus of short-acting insulin to BOT (BOTplus) has received some attention in recent years after interesting and stimulating results were published [Lankisch et al. 2008; Davidson et al. 2011; Owens et al. 2011; Del Prato et al. 2012; Mathieu et al. 2014]. The results were implemented in a therapeutic strategy, dependent on the previous treatment and actual glycemic situation [Ampudia-Blasco et al. 2011].

BIT. Randomized, prospective controlled BIT studies have been performed in recent years for some of the now clinically used or forthcoming GLP-1 RAs: exenatide versus placebo added to 


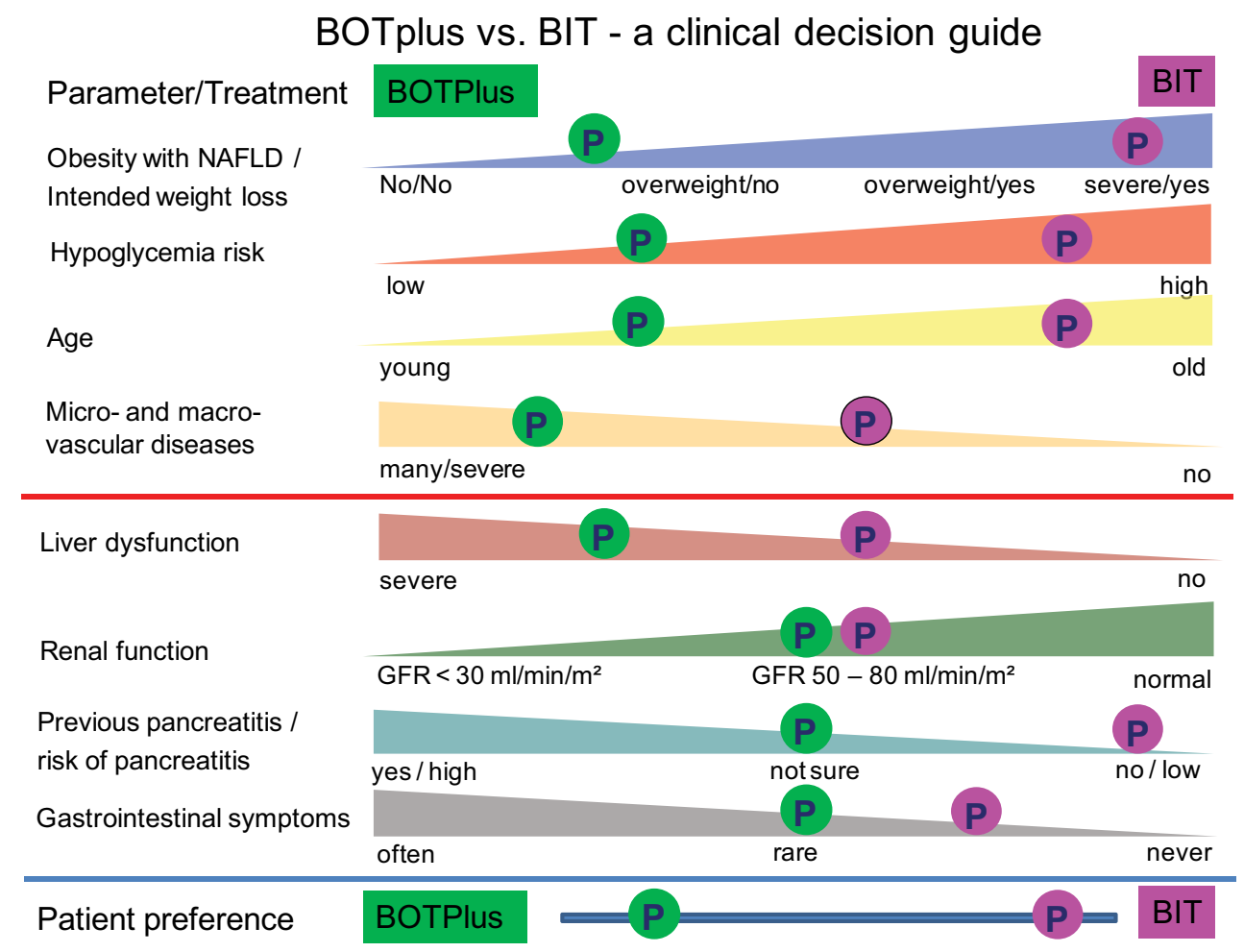

Figure 4. BOTplus versus BIT: a clinical decision guide lexample: green and purple points denote two patients with different characteristics). BIT, basal insulin combined incretin mimetic therapy; BOTplus, basal insulin supported oral therapy with the addition of one bolus of short-acting insulin; GFR, glomerular filtration rate; NAFLD, nonalcoholic fatty liver disease. Graphic design adapted from [Inzucchi et al. 2012; Ismail-Beigi et al. 2011].

insulin glargine and metformin or pioglitazone [Buse et al.2011] or added to insulin glargine and metformin [Riddle et al. 2010]; lixisenatide versus placebo added to basal insulin and SU [Seino et al. 2012] or added to basal insulin and metformin [Riddle et al. 2013a] or added to insulin glargine and metformin or glitazone [Riddle et al. 2013b]; liraglutide, when insulin detemir was given in a previous treatment with liraglutide and metformin in comparison to a group, which continued with unchanged treatment (observational arm) [DeVries et al. 2012]; liraglutide, when added to insulin degludec and metformin versus one single injection of prandial insulin aspart added to insulin degludec and metformin [Mathieu et al. 2014]; and albiglutide versus prandial insulin lispro three times a day added to insulin glargine and OAD medication in some patients [Rosenstock et al. 2014a].

\section{Treatment efficacy}

BOTplus. In the first study of this kind [Lankisch et al. 2008] in two groups of patients with T2DM on BOT with HbA1c slightly above the target range (basal HbAlc $7.3 \%$ in both groups) a single injection of insulin glulisine was given before breakfast or before the main meal. There was a significant and comparable improvement of $\mathrm{HbA} 1 \mathrm{c}$ in the breakfast group $(-0.31 \%)$ and in the main meal-time group $(-0.36 \%)$.

In an additional proof of concept study [Owens et al. 2011] patients with T2DM underwent a 3-month run-in period on insulin glargine, titrated to optimize fasting blood glucose. In patients with $\mathrm{HbA} 1 \mathrm{c}$ at least $7 \%$, the $\mathrm{HbA} 1 \mathrm{c}$ and fasting plasma glucose levels decreased significantly in the 3 months after randomization in both a basal-plus-bolus and a basal-insulin-only group. A significantly greater reduction of $\mathrm{HbAlc}$ was observed in the basal-plus-bolus group versus the basal-insulin-only group $(-0.37 \%$ versus $-0.11 \%$ ) and significantly more participants in the basal-plus-bolus group reached $\mathrm{HbAlc}$ less than $7.0 \%$ than in the basal-insulin-only group (22.4\% versus $8.8 \%)$. 
In an open-label, parallel-group, 1:1:1 randomized study of adults with T2DM on OADs (HbAlc $\geqslant 8 \%$ ), patients with HbAlc above $7 \%$ after a 14 -week titration with insulin glargine were assigned to one, two or three times daily insulin glulisine for 24 weeks [Davidson et al. $2011]$. HbA1c decreased from randomization to week 24 by $-0.44 \%,-0.36 \%$ and $-0.43 \%$ in the three groups, respectively. The HbAlc-lowering effect of the once a day insulin glulisine group (BOTplus) was not inferior to the effect in the other two groups, although the percentage of patients achieving an acceptable overall glycemia $(\mathrm{HbA} 1 \mathrm{c}<7.0 \%)$ at week 24 was $30 \%, 33 \%$ and $46 \%$. However, severe hypoglycemia occurred in twice as many patients in the insulin glulisine three times a day group compared with the other two treatment groups (18 versus 8 versus 9 events) and this group had a significantly higher event rate than the once daily group.

In another randomized trial [Del Prato et al. 2012] insulin glargine was used for about 8-16 weeks to achieve a target fasting plasma glucose of up to 5.6 $\mathrm{mmol} /$ liter $(\leqslant 100 \mathrm{mg} / \mathrm{dl}$ ). In patients with fasting plasma glucose of up to $7 \mathrm{mmol} / \mathrm{liter}(\leqslant 126 \mathrm{mg} /$ dl) one dose of insulin glulisine was added at the meal with the highest postprandial plasma glucose excursion and then titrated to target $2 \mathrm{~h}$ postprandial plasma glucose of less than $7.8 \mathrm{mmol} /$ liter $(<140 \mathrm{mg} / \mathrm{dl})$ monitored by telecare or self-measured blood glucose (SMBG). HbAlc levels were significantly reduced by insulin glargine titration from about $8.8 \%$ to $7.9 \%$ resp. to $7.8 \%$. Addition of insulin glulisine significantly reduced $\mathrm{HbA} 1 \mathrm{c}$ in both groups $(-0.7 \%)$. The target HbA1c $(\leqslant 7 \%)$ was achieved in $45.2 \%$ versus $54.8 \%$ without a significant difference between groups.

In a study with a once-daily injection of shortacting insulin to basal insulin, insulin aspart was added to insulin degludec and continuing metformin [Mathieu et al. 2014]. Addition of the short-acting insulin resulted in a significant reduction of $\mathrm{HbA} 1 \mathrm{c}$ from $7.7 \%$ to $7.3 \%$, whereas fasting blood glucose did not change [steady at $6.1 \mathrm{mmol} /$ liter $(110 \mathrm{mg} / \mathrm{dl})]$. Postprandial plasma glucose was numerically reduced at each meal. The largest reduction in prandial increments was seen at the main evening meal [prandial increment week $0: 2.4 \mathrm{mmol} /$ liter $(43 \mathrm{mg} /$ dl); week 26: $1.4 \mathrm{mmol} / \mathrm{liter}(25 \mathrm{mg} / \mathrm{dl})$ ] with insulin aspart injected pre breakfast by $5.4 \%$, pre lunch by $47.3 \%$ and pre evening meal by $47.3 \%$ of subjects. The nine-point SMBG profile improved from a mean of $8.0 \mathrm{mmol} / \mathrm{liter}$ $(144 \mathrm{mg} / \mathrm{dl})$ to $7.0 \mathrm{mmol} / \mathrm{liter}(126 \mathrm{mg} / \mathrm{dl})$.

In summary, BOTplus is an acceptable alternative to a more intensive insulin treatment and can be used safely and effectively to reduce postprandial hypoglycemia and $\mathrm{HbA} 1 \mathrm{c}$, especially if given at the largest meal.

BIT. GLP-1 RAs added to basal insulin with different OAD medications significantly reduced elevated $\mathrm{HbAlc}$ values in comparison to placebo added to the same medication by $-0.69 \%$ for exenatide versus placebo added to insulin glargine and metformin or pioglitazone [Buse et al. 2011], $-0.88 \%$ for lixisenatide versus placebo added to basal insulin and SU [Seino et al. 2012], $-0.36 \%$ for lixisenatide versus placebo added to basal insulin and metformin [Riddle et al. 2013a], $-0.32 \%$ for lixisenatide versus placebo added to insulin glargine and metformin or glitazone [Riddle et al. $2013 \mathrm{~b}],-0.5 \%$ for liraglutide when insulin detemir was added to a previous treatment with liraglutide and metformin compared with a group that continued with unchanged treatment (observational arm) [DeVries et al. 2012] and $-0.16 \%$ for albiglutide versus prandial insulin lispro added to insulin glargine and OAD [Rosenstock et al. 2014a].

In another study, a once-daily injection of liraglutide was added to insulin degludec and continuing metformin [Mathieu et al. 2014]. The addition of liraglutide resulted in a significant reduction of $\mathrm{HbA} 1 \mathrm{c}$ from $7.7 \%$ to $7.0 \%$, whereas fasting blood glucose did not change significantly $[6.4 \mathrm{mmol} /$ liter $(115 \mathrm{mg} / \mathrm{dl})$ versus $6.3 \mathrm{mmol} / \mathrm{liter}(113 \mathrm{mg} / \mathrm{dl})]$. The largest numerical reduction in prandial increments was seen at breakfast [week 0: $3.9 \mathrm{mmol} / \mathrm{liter}(70$ $\mathrm{mg} / \mathrm{dl}$ ); week 26: $3.1 \mathrm{mmol} / \mathrm{liter}(56 \mathrm{mg} / \mathrm{dl})]$. In addition, there was an improvement in the ninepoint SMBG profile from a mean of $8.0 \mathrm{mmol} / \mathrm{liter}$ $(144 \mathrm{mg} / \mathrm{dl})$ to $7.0 \mathrm{mmol} / \mathrm{liter}(126 \mathrm{mg} / \mathrm{dl})$.

Most of the randomized studies have shown that GLP-1 RAs in combination with basal insulin (BIT) are more effective compared with BOT alone in reducing $\mathrm{HbAlc}$ and body weight and, if the patients are already treated with insulin, sometimes the insulin dose can be reduced considerably [Gallwitz, 2013].

BOTplus versus BIT. Actually there are only two fully published studies comparing BOTplus with BIT. One study is an indirect study comparing BIT (insulin glargine and lixisenatide) 
with BOTplus (insulin glargine and short-acting insulin once a day) on the basis of a propensity score match of data extracted from randomized trials [Raccah et al. 2014]. In this study BIT compared with BOTplus reached a significantly higher score in the number of patients reaching the treatment target of $\mathrm{HbA} 1 \mathrm{c}$ less than $7 \%$ plus having no weight gain and no hypoglycemic events. Additionally the overall likelihood of reaching $\mathrm{HbAlc}$ less than $7 \%$ for the BIT versus BOTplus group was 1.97 times higher. The composite endpoint of $\mathrm{HbAlc}$ less than $7 \%$, no weight gain and no documented symptomatic hypoglycemia was achieved by $29.2 \%$ of patients with BIT versus $15.3 \%$ with BOTplus. For patients in the BIT group compared with the BOTplus group, the likelihood of reaching $\mathrm{HbAlc}$ less than $7 \%$, no weight gain and no symptomatic hypoglycemia was 2.58 times higher in the BIT group compared with the BOTplus group on a highly significant level.

The other trial is a RCT comparing the effects of adding once daily liraglutide (IDeg + Lira) or once daily insulin aspart (IDeg + Asp) with the largest meal in patients with T2DM that is inadequately controlled $(\mathrm{HbAlc} \geqslant 7 \%)$ on BOT (insulin degludec plus metformin) [Mathieu et al. 2014]. IDeg + Lira reduced $\mathrm{HbAlc}$ significantly more than IDeg + Asp $(-0.32 \%$ points, $95 \%$ CI -0.53 to -0.12$)$ with significantly more patients achieving $\mathrm{HbA} 1 \mathrm{c}$ less than $7 \%$ without confirmed hypoglycemia and without weight gain in the IDeg + Lira group $(49.4 \%, 40 / 81)$ compared with the IDeg + Asp group (7.2\%, 6/83).

Regarding efficacy criteria, these two studies support a preferred use of BIT versus BOTplus in patients with T2DM with $\mathrm{HbA} 1 \mathrm{c}$ targets of less than $7 \%$ without weight gain and hypoglycemia.

\section{Practical approach for selection of \\ BIT versus BOTplus in patients with high postprandial glucose values and comorbidities}

In this paper we have already suggested how different treatment options and patient-specific conditions can be integrated in the selection process for different kinds of BIT. This principle can now be extended to the decision-making process regarding advantages and disadvantages of BIT versus BOTplus.

In Figure 4 we selected some patient characteristics, which, according to conclusions from the abovementioned studies and our own practical experience, may be helpful for an individualized therapeutic strategy using BOTplus or BIT. The graphical analogy to a figure in the recently published ADA/EASD consensus statement guidelines on individualized treatment of patients with T2DM [Ismail-Beigi et al. 2011; Inzucchi et al. 2012], although we selected different patient features, should help to remind us that we do not have to only individualize treatment targets. We should and can also use personal features of our patients to individualize drug treatment strategies like BIT and BOTplus.

To use Figures 2 and 4 in your practice, simply make points in the table and on the scale. In summary, the pictures of the points will give you a more or less convincing idea of which kind of therapy may fit most of the needs and preferences of your patients. As an example, we have chosen in Figure 4 two different patients (green points and purple points), where it is relatively easy, according to the resulting picture, to make a decision between BOTplus and BIT.

Although we selected the same comorbid disease conditions in Figures 2 and 4, the consequences of the use of GLP-1 RAs and basal insulin as part of BIT may differ in comparison to their application as first-line medication (if metformin is contraindicated) or as second-line medication (add on to metformin or another $\mathrm{OAD}$ ).

Therefore we have analyzed the available clinical evidence for the use of BOTplus and BIT in relation to each of these comorbid disease conditions. Additionally we have now included the pros and cons of BOTplus in comparison with BIT according to available clinical data.

Obesity

BOTplus. In all the above-mentioned BOTplus studies there was virtually no or only a slight change in body weight and body mass index from baseline to endpoint [Lankisch et al. 2008; Owens et al. 2011; Del Prato et al. 2012]. In the once daily (BOTplus), twice daily, three times daily insulin glulisine added to titrated glargine study [Davdison et al. 2011] body weight increased by $3.8 \mathrm{~kg}, 3.9 \mathrm{~kg}$ and $4.1 \mathrm{~kg}$, respectively. In the study where insulin aspart was added to insulin degludec and metformin (BOTplus), body weight increased by $0.9 \mathrm{~kg}$ [Mathieu et al. 2014].

BIT. In all placebo and active comparator controlled BIT studies there were changes in weight from 
baseline in both groups and differences between groups for exenatide $(-1.78 \mathrm{~kg})$ versus placebo $(+0.96 \mathrm{~kg})$ on insulin glargine and metformin or pioglitazone, difference $2.74 \mathrm{~kg}$ [Buse et al. 2011]; for lixisenatide $(-0.38 \mathrm{~kg})$ versus placebo $(+0.06 \mathrm{~kg})$ on basal insulin \pm SU, difference $-0.43 \mathrm{~kg}$ [Seino et al. 2012]; for lixisenatide $(+0.28 \mathrm{~kg})$ versus placebo $(+1.16 \mathrm{~kg})$ on basal insulin plus SU, difference 0.89 $\mathrm{kg}$ [Riddle et al. 2013b]; for lixisenatide $(-1.80 \mathrm{~kg})$ versus placebo $(-0.52 \mathrm{~kg})$, difference $1.28 \mathrm{~kg}$ [Riddle et al. 2013a]; for liraglutide with insulin detemir $(-0.16 \mathrm{~kg})$ versus liraglutide without insulin detemir $(-0.95 \mathrm{~kg})$, difference $0.8 \mathrm{~kg}$ [DeVries et al. 2012]; for liraglutide $(-2.8 \mathrm{~kg})$ versus once daily insulin aspart $(+0.9 \mathrm{~kg})$ on insulin degludec, difference -3.8 $\mathrm{kg}$ [Mathieu et al. 2014]; and for albiglutide $(-0.73$ $\mathrm{kg})$ versus three times daily prandial lispro $(+0.81 \mathrm{~kg})$ on insulin glargine with some patients on $\mathrm{OAD}$, difference $-1.5 \mathrm{~kg}$ [Rosenstock et al. 2014a].

BOTplus versus BIT. Regarding changes in fat distribution, for example, visceral versus subcutaneous versus liver fat there are no studies in patients on BOTplus or BIT. But according to results of the above-mentioned magnetic resonance spectroscopy studies of fat distribution [Cuthbertson et al. 2012] using GLP-1 RAs in patients treated with metformin, SU or DPP-4 inhibitors, it can be assumed that also in the case of BIT, there will probably be a reduction in visceral fat and especially in liver fat.

This assumption is supported by the observation that in patients with poorly controlled T2DM, treated for 7 months with basal insulin as an add on to metformin, a reduction in liver fat was documented, although body weight increased [Juurinen et al. 2007]. These results together with the reduction in liver fat by GLP-1 RAs suggest that the combination of GLP-1 RAs with basal insulin (BIT) might have favorable effects on body weight and liver fat.

\section{Hypoglycemia}

Overall there is an increasing risk of hypoglycemia with more intensive antidiabetic treatment, especially when SU or insulin is used [Monami et al. 2014b; Geller et al. 2014]. However, as in the ORIGIN trial, although the treatment with insulin glargine versus standard care was associated with an increased risk of severe and nonsevere hypoglycemia, the relative risk of cardiovascular outcomes with hypoglycemia was lower with insulin glargine based glucose-lowering therapy [Mellbin et al. 2013].
So far, BOT as one basis of BOTplus or BIT seems to be an advantageous pretreatment before adding an additional injection of a short-acting insulin (BOTplus) or a GLP-1 RA (BIT) in preventing cardiovascular events.

BOTplus. In all the above-mentioned BOTplus studies the risk of mild or moderate hypoglycemia was very low without severe hypoglycemic events.

BIT. There were no group differences in hypoglycemic events in all the above-mentioned BIT studies.

BOTplus versus BIT. In the matched population of the BIT versus BOTplus study based on a propensity score match of data extracted from randomized trials [Raccah et al. 2014], the likelihood of achieving an $\mathrm{HbA} 1 \mathrm{c}$ less than $7 \%$ and no symptomatic hypoglycemia was 1.9 times and for HbAlc less than $7 \%$ and no severe hypoglycemia was 1.97 times higher for the BIT versus BOTplus group. In the IDeg + Lira versus IDeg + IAsp study the rate of confirmed overall hypoglycemia was 1.0 and 8.15 episodes per patient year of exposure (PYE), respectively. The hypoglycemia risk was considerably and significantly lower by $87 \%$ in the IDeg + Lira group with an estimated risk ratio (IDeg + Lira/IDeg + IAsp) of 0.13 (95\% CI 0.08-0.21). The same was true for nocturnal confirmed hypoglycemia ( 0.17 versus 1.11 per PYE), which was lower by $86 \%$ with an estimated risk ratio of 0.14 (95\% CI 0.05-0.40) [Mathieu et al. 2014].

Taking efficacy criteria (e.g. HbAlc reduction) and comorbidities into account, we would conclude that patients who are obese with a certain higher risk of hypoglycemia or patients who have to avoid hypoglycemic episodes because of other reasons (e.g. preexisting CVD or professional circumstances) should be better candidates for BIT compared with BOTplus, as suggested in our algorithm.

Age

BOTplus. Although there are no special prospective data about an age-dependent effect of BOTplus strategies on glycemic or cardiovascular outcome parameters, the age-related risk of more hypoglycemic events with insulin therapy has to be considered. Especially in patients older than 80 years, the hypoglycemia-associated risk of visiting an emergency department is more than twofold and the risk of being hospitalized is nearly fivefold compared with patients aged 45-64 years [Geller et al. 2014]. Using a subgroup 
identification algorithm in a retrospective, hypothesis-generating study comparing insulinnaive patients treated with mixed insulin (with a short-acting component) targeting postprandial hyperglycemia with a group of patients on basal insulin, younger patients ( $\leqslant 56$ years) with higher levels of fasting insulin $(>11.4 \mu \mathrm{IU} / \mathrm{ml})$ seem to have the greatest benefit in $\mathrm{HbAl} \mathrm{c}$ reduction with mixed insulin [Hardin et al. 2013].

BIT. As already mentioned above, BIT studies evaluating the benefit in older people are missing [Vora, 2013], although there seems to be a certain preference for BIT in the 'young old' (65-79 years) [Thompson et al. 2013].

BOTplus versus BIT. Because of the higher hypoglycemic risk associated with the use of short-acting insulin added to a basal one in BOTplus, at least patients in the older age groups up to age 80 years should have the benefit of more secure therapy with BIT. However, the higher rate of gastrointestinal side effects, renal failure and age- or comorbidity-related unintended weight loss might limit the use of BIT in older age.

\section{Micro- and macrovascular diseases}

Vascular diseases are often recognized before the manifestation or the diagnosis of T2DM and are some of the main comorbidities predicting the further outcome of the patient. Their presence has influence on the decision-making process for treatment strategies because of safety reasons and the need for further protection.

BOTplus. According to a recent Cochrane update based on RCTs comparing intensive versus conventional treatment of patients with T2DM [Hemmingsen et al. 2013], the intensive treatment, including insulin treatment, seemed to reduce the risk of microvascular complications, whereas there was no effect on macrovascular diseases.

BIT. The favorable effects of GLP-1 RAs on many risk factors for CVDs and also the more specific protective effects on the cardiovascular system as mentioned above should be retained also in combination with basal insulin. Long-term studies are awaited.

BOTplus versus BIT. At least theoretically BIT might be favorable in the long-term regarding cardiovascular safety and protection in comparison to BOTplus because of reduced risk of hypoglycemia, weight loss and improvement in metabolic and hemodynamic risk factors. This view is supported by the above mentioned retrospective [Raccah et al. 2014] and prospective [Mathieu et al. 2014] comparisons of the two treatment strategies.

\section{Renal and hepatic failure}

BOTplus. As with all insulin treatment strategies renal failure has to be taken into account in BOT because of the reduced degradation of insulin and the associated risk of hypoglycemia, which are dependent on renal function. On the other hand insulin and also BOTplus is rather indicated in renal failure, when other antidiabetic medication fails or is contraindicated [Williams and Garg, 2014]. In hepatic failure one has to consider the reduced capacity of gluconeogenesis and the reduced amount of liver glycogen, as well as problems with glycogenolysis to prevent hypoglycemia. But as in renal failure, insulin therapy might be the only option for safe and effective diabetes treatment.

BIT. The use of GLP-1 RAs in renal failure and consequently also the use of BIT is very limited. All GLP-1 RA treatments are not suggested for patients with hepatic failure because of scarcity of information (see above).

BOTplus versus BIT. In the case of renal or hepatic failure, BOTplus is the preferred option, compared with BIT, for antidiabetic treatment.

\section{Pancreatic and gastrointestinal dysfunction}

BOTplus. There is no restriction in the use of insulin and BOTplus in patients with pancreatic or gastrointestinal dysfunction. Nevertheless, in the former, a reduced glucagon response and changes in digestion have to be considered, and in the latter, an unpredictable resorption of nutrients.

BIT. Although safety concerns, as already mentioned, are now widely diminished, GLP-1 RAs alone or in BIT are not suggested for use in patients with previous or current dysfunctions of the pancreas, stomach and gut.

BOTplus versus BIT. Because of the possibility of enhanced side effects in patients with pancreatic or gastrointestinal dysfunction, BOTplus should be the preferred treatment option in these patients with diabetes compared with BIT. 


\section{Patient's preference}

All the above-mentioned guidelines, consensus reports, position statements and recommendations suggest a discussion of benefits, disadvantages and risks of a suggested therapy with the patient as part of individualized therapeutic concepts. Regarding the choice between basal insulin combined incretin mimetic therapy with GLP-1 RAs (BIT) and BOTplus, the authors of a recently published paper suggested a very useful sample checklist for determining patient preference [Hirsch et al. 2014], which in the last line of Figure 4 is the crucial parameter. We suggest using the checklist for the evaluation of patient preference.

\section{Limitations, open questions and perspectives}

Although GLP-1 RAs have been available in clinical practice for some years, the knowledge about their value for the treatment of different stages and phenotypes of T2DM and metabolic vascular syndrome is limited. Our suggestions for a table and chart supported decision guide are an attempt to bridge the gap between practical needs and scientific knowledge. They are based on extrapolation from pathophysiology, clinical studies and personal experience and will have to be improved by information from new scientific and clinical data but also from the growing experience of our readers. Regarding interesting perspectives of GLP-1 RAs and BIT, new data support the use of GLP-1 RAs in BIT as an alternative not only for BOTplus but also for intensive conventional insulin treatment in patients with T2DM [Rosenstock et al. 2014a]. Also for patients with T1DM, the BIT concept might provide a very interesting therapeutic alternative in reducing the total daily dose of insulin and the risk of hypoglycemia [Unger, 2013]. Moreover GLP-1-based therapies may be therapeutic options for nonalcoholic fatty liver disease [Armstrong et al. 2013] and obesity with and without diabetes [Madsbad, 2014]. In respect of a more specific therapy for different types of diabetes, a recently published difference in glucagon response of patients with maturity onset diabetes of the young (MODY), with MODY 2 caused by mutations in the glucokinase gene and MODY 3 caused by mutations in the hepatocyte nuclear factor $\alpha$ gene (HNF1A diabetes) demonstrated the 'typical' paradoxical increase of glucagon in patients with MODY 3 but not in those with MODY 2 [Østoft et al. 2014a]. These observations seem to be the pathophysiological basis of the successful use of liraglutide in a patient with MODY 3 [Docena et al. 2014] and in a small randomized series of such patients in comparison with glimepiride with less hypoglycemia [Østoft et al. 2014b] reported recently. The new data may open up new avenues in the differential therapy of monogenetic types of diabetes.

Last but not least, there is much hope that GLP1-based therapies may reduce the cardiovascular burden in our patients with diabetes, based on many plausible arguments, in vitro observations and initial data for vascular protection in vivo, with some contradictory study results [Forst et al. 2012; Oyama et al. 2014]. Large-scaled randomized, prospective, clinical studies and their subanalyses are under way to answer the many open questions in the near future [Tibaldi, 2014].

\section{Summary}

GLP-1 RAs added to basal insulin, or vice vers $a$, for which we use for the first time the abbreviation BIT, is a new therapeutic strategy. It might be the first step to a more individualized therapy of incretin-supported insulin therapy or insulin-supported incretin therapy (ISI, according to Mehnert) [Mehnert, 2012], when (in the future) the use of insulin is not restricted to basal insulin but also includes normal or short-acting insulins. Moreover, the BIT concept might even be extended to T1DM, as suggested from initial clinical studies.

We see BIT as a useful extension of BOT, especially in patients with T2DM and metabolic vascular syndrome [Scholz, 2010]. In contrast to the combination of a basal insulin with a short-acting insulin taken during the main meal (BOTplus), BIT has the advantage of a lower risk of hypoglycemia, contributes to weight stability or even facilitates weight loss, and opens up a chance for reduction of liver fat and hepatic insulin resistance. BIT is limited to patients without more severe renal or hepatic failure or enhanced gastrointestinal and pancreatic disease susceptibility. The overall decision to administer a GLP-1 RA or a short-acting insulin to basal insulin depends not only on treatment targets but also on the patient's personal and surrounding conditions and the patient's preferences. Careful consideration of each of these factors is necessary and can even be very helpful in the right adjustment of therapeutic targets and the selection of the most effective and convenient therapeutic regime. In our article we describe some of these features and present chart-supported algorithms and examples of how to use GLP-1 RAs and BIT in comparison to BOTplus for a more individualized treatment in our daily clinical practice. 


\section{Conflict of interest statement}

G.H.S. received lecture or consulting honoraria from Abbott GmbH \& Co.KG, Actavis Deutschland $\mathrm{GmbH} \&$ Co.KG, AstraZeneca GmbH, BerlinChemie AG, BMS GmbH \& Co.KGaA, Essex Pharma Distributions $\mathrm{GmbH}$, Lilly Deutschland GmbH, MSD Sharp \& Dohme GmbH, Novartis Pharma GmbH, Novo Nordisk Pharma GmbH, Sanofi Aventis Deutschland $\mathrm{GmbH}$, Solvay Arzneimittel GmbH, Takeda Pharma GmbH. H.F. is an employee of Sanofi Aventis Deutschland $\mathrm{GmbH}$. Both authors contributed equally to the content and the edition of the manuscript.

\section{Funding}

This research received no specific grant from any funding agency in the public, commercial, or notfor-profit sectors.

\section{References}

Ahrén, B. (2014) Insulin plus incretin: a glucoselowering strategy for type 2 -diabetes. World $\mathcal{F}$ Diabetes 5: 40-51.

Ahrén, B., Gautier, J., Berria, R., Stager, W., Aronson, R. and Bailey, C. (2014a) Pronounced reduction of postprandial glucagon by lixisenatide: a meta-analysis of randomized clinical trials. Diabetes Obes Metab 16: 861-868.

Ahrén, B., Johnson, S., Stewart, M., Cirkel, D., Yang, F., Perry, C. et al. (2014b) 104-week randomized, double-blind, placebo- and active-controlled trial assessing the efficacy and safety of albiglutide compared with placebo, sitagliptin, and glimepiride in patients with type 2 diabetes taking metformin. Diabetes Care. 37: 2141-2148.

American Diabetes Association (2014) Clinical practice recommendations - standards of medical care in diabetes. Diabetes Care 37: S14-S80.

Ampudia-Blasco, F., Rossetti, P. and Ascaso, J. (2011) Basal plus basal-bolus approach in type 2 diabetes. Diabetes Technol Ther 13(Suppl. 1): S75-S83.

Armstrong, M., Barton, D., Gaunt, P., Hull, D., Guo, K., Stocken, D. et al. (2013) Liraglutide efficacy and action in non-alcoholic steatohepatitis (LEAN): study protocol for a phase II multicentre, double-blinded, randomised, controlled trial. BMF Open 3: e003995.

Balena, R., Hensley, I., Miller, S. and Barnett, A. (2013) Combination therapy with GLP-1 receptor agonists and basal insulin: a systematic review of the literature. Diabetes Obes Metabol 15: 485-502.

Balkau, B., Hu, G., Qiao, Q., Tuomilehto, J., BorchJohnsen, K. and Pyörälä, K., DECODE Study Group; European Diabetes Epidemiology Group (2004)
Prediction of the risk of cardiovascular mortality using a score that includes glucose as a risk factor. The DECODE Study. Diabetologia 47: 2118-2128.

Barnett, A. (2012) The role of GLP-1 mimetics and basal insulin analogues in type 2 diabetes mellitus: guidance from studies of liraglutide. Diabetes Obes Metab 14: 304-314.

Becker, R., Stechl, J., Msihid, J. and Kapitza, C. (2014) Lixisenatide resensitizes the insulin-secretory response to intravenous glucose challenge in people with type 2 diabetes - a study in both people with type 2 diabetes and healthy subjects. Diabetes Obes Metab 16: 793-800.

Berg, J., Shenouda, S., Heilmann, C., Gray, A. and Holcombe, J. (2011) Effects of exenatide twice daily versus sitagliptin on 24-h glucose, glucoregulatory and hormonal measures: a randomized, double-blind, crossover study. Diabetes Obes Metab 11: 982-989.

Bernsmeier, C., Meyer-Gerspach, A., Blaser, L., Jeker, L., Steinert, R. et al. (2014) Glucose-induced glucagon-like peptide 1 secretion is deficient in patients with non-alcoholic fatty liver disease. PLoS One 9: e87488.

Best, J., Hoogwerf, B., Herman, W., Pelletier, E., Smith, D., Wenten, M. et al. (2011) Risk of cardiovascular disease events in patients with type 2 diabetes prescribed the glucagon-like peptide 1 (GLP-1) receptor agonist exenatide twice daily or other glucose-lowering therapies: a retrospective analysis of the LifeLink database. Diabetes Care 34: 90-95.

Bonds, D., Miller, M., Dudl, J., Feinglos, M., Ismail-Beigi, F., Malozowski, S. et al. (2012) Severe hypoglycemia symptoms, antecedent behaviors, immediate consequences and association with glycemia medication usage: secondary analysis of the ACCORD clinical trial data. BMC Endocr Disord 12: 5.

Bonora, E., Corrao, G., Bagnardi, V., Ceriello, A., Comaschi, M., Montanari, P. et al. (2006) Prevalence and correlates of postprandial hyperglycaemia in a large sample of patients with type 2 diabetes mellitus. Diabetologia 49: 846-854.

Brooks, A. and Lissett, C. (2009) A dramatic deterioration in diabetic retinopathy with improvement in glycated haemoglobin $(\mathrm{HbA}(1 \mathrm{c}))$ on exenatide treatment. Diabet Med 26: 190.

Brown, D., Butler, E. and Evans, M. (2013) Lixisenatide as add-on therapy to basal insulin. Drug Des Devel Ther 8: 25-38.

Brunton, S. (2014) GLP-1 receptor agonists versus DPP-4 inhibitors for type 2 diabetes: is one approach more successful or preferable than the other? Int $\mathcal{F}$ Clin Pract 68: 557-567. 
Bunck, M., Diamant, M., Eliasson, B., Cornér, A., Shaginian, R., Heine, R. et al. (2010) Exenatide affects circulating cardiovascular risk biomarkers independently of changes in body composition. Diabetes Care 33: 1734-1737.

Burgmaier, M., Heinrich, C. and Marx, N. (2013) Cardiovascular effects of GLP-1 and GLP-1based therapies: implications for the cardiovascular continuum in diabetes? Diabet Med 30: 289-299.

Buse, J., Bergenstal, R., Glass, L., Heilmann, C., Lewis, M., Kwan, A. et al. (2011) Use of twice-daily exenatide in basal insulin-treated patients with type 2 diabetes: a randomized, controlled trial. Ann Intern Med 154: 103-112.

Buse, J., Klonoff, D., Nielsen, L., Guan, X., Bowlus, C., Holcombe, J. et al. (2007) Metabolic effects of two years of exenatide treatment on diabetes, obesity, and hepatic biomarkers in patients with type 2 diabetes: an interim analysis of data from the open-label, uncontrolled extension of three double-blind, placebo-controlled trials. Clin Ther 29: 139-153.

Buse, J., Rosenstock, J., Sesti, G., Schmidt, W., Montanya, E., Brett, J. et al.(2009) Liraglutide once a day versus exenatide twice a day for type 2 diabetes: a 26-week randomised, parallel-group, multinational, open-label trial (LEAD-6). Lancet 374: 39-47.

Butler, P., Elashoff, M., Elashoff, R. and Gale, E. (2013) A critical analysis of the clinical use of incretinbased therapies: are the GLP-1 therapies safe? Diabetes Care 36: 2118-2125.

Cavalot, F., Pagliarino, A., Valle, M., Di Martino, L., Bonomo, K., Massucco, P. et al. (2011) Postprandial blood glucose predicts cardiovascular events and all-cause mortality in type 2 diabetes in a 14-year follow-up: lessons from the San Luigi Gonzaga Diabetes Study. Diabetes Care 34: 2237-2243.

Cavalot, F., Petrelli, A., Traversa, M., Bonomo, K., Fiora, E., Conti, M. et al. (2006) Postprandial blood glucose is a stronger predictor of cardiovascular events than fasting blood glucose in type 2 diabetic mellitus, particularly in women: lessons from the San Luigi Gonzaga Diabetes Study. F Clin Endocrinol Metab 91: 813-819.

Ceriello, A. (2010) The glucose triad and its role in comprehensive glycaemic control: current status, future management. Int f Clin Pract 64: 1705-1711.

Ceriello, A., Hanefeld, M., Leiter, L., Monnier, L., Moses, A., Owens, D. et al. (2004) Postprandial glucose regulation and diabetic complications. Arch Intern Med 164: 2090-2095.

Cervera, A., Wajcberg, E., Sriwijitkamol, A., Fernandez, M., Zuo, P., Triplitt, C. et al. (2008) Mechanism of action of exenatide to reduce postprandial hyperglycemia in type 2 diabetes. $A m \mathcal{F}$ Physiol Endocrinol Metab 294: E846-E852.

Chiasson, J., Josse, R., Gomis, R., Hanefeld, M., Karasik, A. and Laakso, M. (2003) Acarbose treatment and the risk of cardiovascular disease and hypertension in patients with impaired glucose tolerance: the STOPNIDDM trial. $\mathcal{F} A M A$ 290: 486-494.

Coates, P., Ollerton, R., Luzio, S., Ismail, I. and Owens, D. (1994) A glimpse of the 'natural history' of established type 2 (non-insulin dependent) diabetes mellitus from the spectrum of metabolic and hormonal responses to a mixed meal at the time of diagnosis. Diabetes Res Clin Pract 26: 177-187.

Cohen, N., Audehm, R., Pretorius, E., Kaye, J., Chapman, L. and Colagiuri, S. (2013) The rationale for combining GLP-1 receptor agonists with basal insulin. Med F Aust 199: 246-249.

Cuthbertson, D., Irwin, A., Gardner, C., Daousi, C., Purewal, T., Furlong, N. et al. (2012) Improved glycaemia correlates with liver fat reduction in obese, type 2 diabetes, patients given glucagon-like peptide-1 (GLP-1) receptor agonists. PLoS One 7: e50117.

Davidson, M., Raskin, P., Tanenberg, R., Vlajnic, A. and Hollander, P. (2011) A stepwise approach to insulin therapy in patients with type 2 diabetes mellitus and basal insulin treatment failure. Endocrine Practice 17: 395-403.

DeFronzo, R., Okerson, T., Viswanathan, P., Guan, X., Holcombe, J. and MacConell, L. (2008) Effects of exenatide versus sitagliptin on postprandial glucose, insulin and glucagon secretion, gastric emptying, and caloric intake: a randomized, cross-over study. Curr Med Res Opin 24: 2943-2952.

Degn, K., Juhl, C., Sturis, J., Jakobsen, G., Brock, B., Chandramouli, V. et al. (2004) One week's treatment with the long-acting glucagon-like peptide 1 derivative liraglutide (NN2211) markedly improves 24-h glycemia and alpha- and beta-cell function and reduces endogenous glucose release in patients with type 2 diabetes. Diabetes 53: 1187-1194.

de Heer, J., Rasmussen, C., Coy, D. and Holst, J. (2008) Glucagon-like peptide-1, but not glucosedependent insulinotropic peptide, inhibits glucagon secretion via somatostatin (receptor subtype 2 ) in the perfused rat pancreas. Diabetologia 51: 2263-2270.

Del Prato, S. (2003) Loss of early insulin secretion leads to postprandial hyperglycaemia. Diabetologia 46(Suppl. 1): M2-M8.

Del Prato, S., Nicolucci, A., Lovagnini-Scher, A., Turco, S., Leotta, S. and Vespasiani, G. (2012) Telecare provides comparable efficacy to conventional self-monitored blood glucose in patients with type 2 diabetes titrating one injection of insulin glulisine 
- the ELEONOR study. Diabetes Technol Ther 14: 175-182.

DeVries, J., Bain, S., Rodbard, H., Seufert, J., D'Alessio, D., Thomsen, A. et al. (2012) Sequential intensification of metformin treatment in type 2 diabetes with liraglutide followed by randomized addition of basal insulin prompted by A1C targets. Diabetes Care 35: 1446-1454.

Distiller, L. and Ruus, P. (2008) Pharmacokinetics and pharmacodynamics of a new GLP-1 agonist AVE0010 in type 2 diabetes patients. Diabetes 57(Suppl. 1): A154-A155.

Docena, M., Faiman, C., Stanley, C. and Pantalone, K. (2014) Mody-3: novel HNF1A mutation and the utility of glucagon-like peptide (GLP)-1 receptor agonist therapy. Endocr Pract 20: 107-111.

Drucker, D. (2013) Incretin action in the pancreas: potential promise, possible perils, and pathological pitfalls. Diabetes 62: 3316-3323.

Drucker, D., Buse, J., Taylor, K., Kendall, D., Trautmann, M., Zhuang, D. et al. (2008) Exenatide once weekly versus twice daily for the treatment of type 2 diabetes: a randomised, open-label, noninferiority study. Lancet 372: 1240-1250.

Dubois-Laforgue, D., Boutboul, D., Lévy, D., Joly, D. and Timsit, J. (2013) Severe acute renal failure in patients treated with glucagon-like peptide-1 receptor agonists. Diabetes Res Clin Pract 103: e53-e55.

Duckworth, W., Abraira, C., Moritz, T., Reda, D., Emanuele, N., Reaven, P. et al. (2009) Glucose control and vascular complications in veterans with type 2 diabetes. $N$ Engl F Med 360: 129-139.

Egan, A., Blind, E., Dunder, K., de Graeff, P., Hummer, B., Bourcier, T. et al. (2014) Pancreatic safety of incretin-based drugs - FDA and EMA assessment. N Engl f Med 370: 794-797.

Elashoff, M., Matveyenko, A., Gier, B., Elashoff, R. and Butler, P. (2011) Pancreatitis, pancreatic, and thyroid cancer with glucagon-like peptide-1-based therapies. Gastroenterology 141: 150-156.

Eng, J. and Eng, C. (1992) Exendin-3 and -4 are insulin secretagogues. Regulatory Peptides 40: 142.

EMA (2014a) 23 January EMA/CHMP/20616/2014 Committee for Medicinal Products for Human Use (CHMP): summary of opinion 1 (initial authorisation). Eperzan albiglutide. European Medicines Agency. Available at: http://www.ema. europa.eu/ema/index.jsp?curl=pages/medicines/ human/medicines/002735/smops/Positive/human_ smop_000634.jsp\&mid=WC0b01 ac058001d127 (accessed 10 October 2014).

EMA (2014b) 20 March EMA/CHMP/164151/2014: summary of opinion (post authorisation). Victoza liraglutide. European Medicines Agency. Available at: http://www.ema.europa.eu/ema/index.jsp?curl=pages/ medicines/human/medicines/001026/smops/Positive/ human_smop_000661.jsp\&mid=WC0b01ac058001d127 (accessed 10 October 2014).

EMA (2014c) 20 March EMA/CHMP/164154/2014: summary of opinion (post authorization). Tresiba insulin degludec. European Medicines Agency. Available at: http://www.ema.europa.eu/ema/index.jsp?curl=pages/ medicines/human/medicines/002498/smops/Positive/ human_smop_000660.jsp\&mid=WC0b01ac058001d127 (accessed 10 October 2014).

Fachkommission Diabetes Sachsen, Saxony, Germany (2009) Praxisleitlinie Diabetes mellitus Type 2. Auflage 11 Available at: http://www.ag-sachsen.de/ index.php/praxisleitlinien-pdf.html (accessed 16 October 2014).

Fachkommission Diabetes Sachsen, Saxony, Germany (2007, 2013) Practical Guideline Metabolic Vascular Syndrome (MVS) 1th Edition (2007), Praxisleitlinie Metabolisch Vaskuläres Syndrom (MVS) 2. Auflage (2013). Available at: http://www.ag-sachsen.de/index. php/praxisleitlinien-pdf.html (accessed 16 October 2014).

FDA (2014) News release 15 April. FDA approves Tanzeum to treat type 2 diabetes. Food and Drug Administration. Available at: http:/www.fda. gov/newsevents/newsroom/pressannouncements/ ucm393289.htm (accessed 10 October 2014).

Fehse, F., Trautmann, M., Holst, J., Halseth, A., Nanayakkara, N., Nielsen, L. et al. (2005) Exenatide augments first- and second-phase insulin secretion in response to intravenous glucose in subjects with type 2 diabetes. $\mathcal{F}$ Clin Endocrinol Metab 90: 5991-5997.

Feinkohl, I., Aung, P., Keller, M., Robertson, C., Morling, J., McLachlan, S. et al. (2014) Severe hypoglycemia and cognitive decline in older people with type 2 diabetes: the Edinburgh Type 2 Diabetes Study. Diabetes Care 37: 507-515.

Filippatos, T. and Elisaf, M. (2013) Effects of glucagon-like peptide-1 receptor agonists on renal function. World f Diabetes 4: 190-201.

Fineman, M., Cirincione, B., Maggs, D. and Diamant, M. (2012) GLP-1 based therapies: different effects on fasting and postprandial glucose. Diabetes Obes Metab 14: 675-688.

Flint, A., Kapitza, C., Hindsberger, C. and Zdravkovic, M. (2011) The once-daily human glucagon-like peptide-1 (GLP-1) analog liraglutide improves postprandial glucose levels in type 2 diabetes patients. Adv Ther 28: 213-226.

Fonseca, V. (2014) New developments in diabetes management: medications of the 21 st century. Clin Ther 36: 477-484. 
Fonseca, V., Gill, J., Zhou, R. and Leahy, J. (2011) An analysis of early insulin glargine added to metformin with or without sulfonylurea: impact on glycaemic control and hypoglycaemia. Diabetes Obes Metab 13: 814-822.

Forst, T., Weber, M. and Pfützner, A. (2012)

Cardiovascular benefits of GLP-1-based therapies in patients with diabetes mellitus type 2: effects on endothelial and vascular dysfunction beyond glycemic control. $\operatorname{Exp}$ Diabetes Res. 2012: 635472.

Fujita, H., Morii, T., Fujishima, H., Sato, T., Shimizu, T., Hosoba, M. et al. (2014) The protective roles of GLP-1R signaling in diabetic nephropathy: possible mechanism and therapeutic potential. Kidney Int 85: 579-589.

Gallwitz, B. (2013) Incretin for the continuing treatment of secondary failure to metformin in type 2 diabetes. Diabetes Management 3: 323-331.

Garber, A., Abrahamson, M., Barzilay, J., Blonde, L., Bloomgarden, Z., Bush, M. et al. (2013)

American Association of Clinical Endocrinologists' comprehensive diabetes management algorithm 2013 consensus statement - executive summary. Endocr Pract 19: 536-557.

Geller, A.I., Shehab, N., Lovegrove, M.C., Kegler, S.R., Weidenbach, K.N., Ryan, G.J. and Budnitz, D.S. (2014) National estimates of insulin-related hypoglycemia and errors leading to emergency department visits and hospitalizations. FAMA Intern Med 174: 678-686.

Gerstein, H.C., Miller, M.E., Byington, R.P., Goff, D.C. Jr, Bigger, J.T., Buse, J.B. et al. (2008) Effects of intensive glucose lowering in type 2 diabetes. $N$ Engl f Med 358: 2545-2559.

Gerstein, H., Bosch, J., Dagenais, G., Díaz, R., Jung, H., Maggioni, A. et al. (2012) Basal insulin and cardiovascular and other outcomes in dysglycemia. $N$ Engl f Med 367: 319-328.

Ghazi, T., Rink, L., Sherr, J. and Herold, K. (2014) Acute metabolic effects of exenatide in patients with type 1 diabetes with and without residual insulin to oral and intravenous glucose challenges. Diabetes Care 37: 210-216.

Giorda, C., Nada, E. and Tartaglino, B. (2014) Pharmacokinetics, safety, and efficacy of DPP-4 inhibitors and GLP-1 receptor agonists in patients with type 2 diabetes mellitus and renal or hepatic impairment. A systematic review of the literature. Endocrine 46: 406-419.

Göke, R., Fehmann, H.C., Linn, T., Schmidt, H., Krause, M., Eng, J. et al. (1993) Exendin-4 is a high potency agonist and truncated exendin-(9-39)-amide an antagonist at the glucagon-like peptide 1-(7-36)amide receptor of insulin-secreting beta-cells. $\mathcal{F}$ Biol Chem 15; 268: 19650-19655.
Hanefeld, M., Duetting, E. and Bramlage, P. (2013)

Cardiac implications of hypoglycaemia in patients with diabetes - a systematic review. Cardiovasc Diabetol 12: 135.

Hanefeld, M., Fleischmann, H., Landgraf, W. and Pistrosch, F. (2012) EARLY Study: early basal insulin therapy under real-life conditions in type 2 diabetics. Diabetes, Stoffwechsel und Herz 21: 91-97.

Hanefeld, M., Fleischmann, H., Schiffhorst, G. and Bramlage, P. (2014) Predictors of response to early basal insulin treatment in patients with type 2 diabetes - the EARLY experience. Diabetes Technol Ther 16: 241-246.

Hanefeld, M., Koehler, C., Henkel, E., Fuecker, K., Schaper, F. and Temelkova-Kurktschiev, T. (2000) Post-challenge hyperglycaemia relates more strongly than fasting hyperglycaemia with carotid intima-media thickness: the RIAD Study. Risk Factors in Impaired Glucose Tolerance for Atherosclerosis and Diabetes. Diabet Med 17: 835-840.

Hanefeld, M., Koehler, C., Hoffmann, C., Wilhelm, K., Kamke, W. and Gerstein, H. (2010) Effect of targeting normal fasting glucose levels with basal insulin glargine on glycaemic variability and risk of hypoglycaemia: a randomized, controlled study in patients with early type 2 diabetes. Diabet Med 27: 175-180.

Hanefeld, M. and Leonhardt, W. (1981) Das metabolische Syndrom. Dt Gesundheitswesen 36: 545-551.

Hardin, D., Rohwer, R., Curtis, B., Zagar, A., Chen, L., Boye, K. et al. (2013) Understanding heterogeneity in response to antidiabetes treatment: a post hoc analysis using SIDES, a subgroup identification algorithm. F Diabetes Sci Technol 7: 420-430.

Heller, R., Kieffer, T. and Habener, J. (1997) Insulinotropic glucagon-like peptide I receptor expression in glucagon-producing alpha-cells of the rat endocrine pancreas. Diabetes 46: 785-791.

Hellman, B. and Grapengiesser, E. (2014) Glucoseinduced inhibition of insulin secretion. Acta Physiol (Oxf) 210: 479-488.

Hemmingsen, B., Lund, S.S., Gluud, C., Vaag, A., Almdal, T.P., Hemmingsen, C. et al. (2013) Targeting intensive glycaemic control versus targeting conventional glycaemic control for type 2 diabetes mellitus. Cochrane Database of Systematic Reviews (11): CD008143. DOI: 10.1002/14651858.CD008143.pub3.

Hirsch, I., Buse, J., Leahy, J., McGill, J., Peters, A., Rodbard, H. et al. (2014) Options for prandial glucose management in type 2 diabetes patients using basal insulin: addition of a short-acting GLP-1 analogue versus progression to basal-bolus therapy. Diabetes Obes Metab 16: 206-214. 
Holman, R., Paul, S., Bethel, M., Matthews, D. and Neil, H. (2008) 10-year follow-up of intensive glucose control in type 2 diabetes. $N$ Engl F Med 359: 1577-1589.

Holst, J. and Vilsbøll, T. (2013) Combining GLP-1 receptor agonists with insulin: therapeutic rationales and clinical findings. Diabetes Obes Metab 15: 3-14.

Hopkins, N., Cuthbertson, D., Kemp, G., Pugh, C., Green, D., Cable, N. et al. (2013) Effects of 6 months glucagon-like peptide-1 receptor agonist treatment on endothelial function in type 2 diabetes mellitus patients. Diabetes Obes Metab 15: 770-773.

Inoue, K., Maeda, N., Kashine, S., Fujishima, Y., Kozawa, J., Hiuge-Shimizu, A. et al. (2011) Short-term effects of liraglutide on visceral fat adiposity, appetite, and food preference: a pilot study of obese Japanese patients with type 2 diabetes. Cardiovasc Diabetol 10: 109.

International Diabetes Federation (2011) Guideline for Management of Postmeal Glucose in Diabetes. http:// www.idf.org/2011-guideline-management-postmealglucose-diabetes (accessed 10 October 2014).

Inzucchi, S., Bergenstal, R., Buse, J., Diamant, M., Ferrannini, E., Nauck, M. et al. (2012) Management of hyperglycaemia in type 2 diabetes: a patient-centered approach. Position statement of the American Diabetes Association (ADA) and the European Association for the Study of Diabetes (EASD). Diabetologia 55: 1577-1596.

Ismail-Beigi, F., Moghissi, E., Tiktin, M., Hirsch, I., Inzucchi, S. and Genuth, S. (2011) Individualizing glycemic targets in type 2 diabetes mellitus: implications of recent clinical trials. Ann Intern Med 154: 554-559.

Jimenez-Solem, E., Rasmussen, M., Christensen, M. and Knop, F. (2010) Dulaglutide, a long-acting GLP-1 analog fused with an Fc antibody fragment for the potential treatment of type 2 diabetes. Curr Opin Mol Ther 12: 790-797.

Jones, K., Horowitz, M., Carney, B., Wishart, J., Guha, S. and Green, L. (1996) Gastric emptying in early noninsulin dependent diabetes mellitus. $\mathcal{F} \mathrm{Nucl}$ Med 37: 1643-1648.

Juurinen, L., Tiikkainen, M., Häkkinen, A., Hakkarainen, A. and Yki-Järvinen, H. (2007) Effects of insulin therapy on liver fat content and hepatic insulin sensitivity in patients with type 2 diabetes. $\mathrm{Am}$ F Physiol Endocrinol Metab 292: E829-E835.

Kahn, S., Haffner, S., Heise, M., Herman, W., Holman, R., Jones, N. et al. (2006) Glycemic durability of rosiglitazone, metformin, or glyburide monotherapy. N Engl F Med 355: 2427-2443.

Kanat, M., Mari, A., Norton, L., Winnier, D., DeFronzo, R., Jenkinson, C. et al. (2012) Distinct $\beta$-cell defects in impaired fasting glucose and impaired glucose tolerance. Diabetes 61: 447-453.
Kapitza, C., Forst, T., Coester, H., Poitiers, F., Ruus, P. and Hincelin-Mery, A. (2013) Pharmacodynamic characteristics of lixisenatide once daily versus liraglutide once daily in patients with type 2 diabetes insufficiently controlled on metformin. Diabetes Obes Metab 15: 642-649.

Kenny, P., Brady, D., Torres, D., Ragozzino, L., Chalasani, $\mathrm{N}$. and Harrison, S. (2010) Exenatide in the treatment of diabetic patients with non-alcoholic steatohepatitis: a case series. Am f Gastroenterol 105: 2707-2709.

Khoo, E., Wallis, J., Tsintzas, K., Macdonald, I. and Mansell, P. (2010) Effects of exenatide on circulating glucose, insulin, glucagon, cortisol and catecholamines in healthy volunteers during exercise. Diabetologia 53: 139-143.

Kirkman, M., Briscoe, V., Clark, N., Florez, H., Haas, L., Halter, J. et al. (2012) Diabetes in older adults: a consensus report. F Am Geriatr Soc 60: 2342-2356.

Koch, C. and Uwaifo, G. (2008) Are gastrointestinal symptoms related to diabetes mellitus and glycemic control? Eur f Gastroenterol Hepatol 20: 822-825.

Kondo, Y., Satoh, S., Nagakura, J., Kimura, M., Nezu, U. and Terauchi, Y. (2013) Defining criteria for the introduction of liraglutide using the glucagon stimulation test in patients with type 2 diabetes. f Diabetes Investig 4: 571-575.

Kostev, K., Dippel, F. and Rathmann, W. (2014) Predictors of hypoglycaemia in insulin-treated type 2 diabetes patients in primary care: a retrospective database analysis. Prim Care Diabetes 8: 127-131.

Kozawa, J., Inoue, K., Iwamoto, R., Kurashiki, Y., Okauchi, Y., Kashine, S. et al. (2012) Liraglutide is effective in type 2 diabetic patients with sustained endogenous insulin-secreting capacity. F Diabetes Investig 3: 294-297.

Lankisch, M., Ferlinz, K., Leahy, J. and Scherbaum, W. (2008) Introducing a simplified approach to insulin therapy in type 2 diabetes: a comparison of two single-dose regimens of insulin glulisine plus insulin glargine and oral antidiabetic drugs. Diabetes Obes Metab 10: 1178-1185.

Lee, M., Wu, Y. and Fried, S. (2013) Adipose tissue heterogeneity: implication of depot differences in adipose tissue for obesity complications. Mol Aspects Med 34: 1-11.

Li, L., Shen, J., Bala, M., Busse, J., Ebrahim, S., Vandvik, P. et al. (2014) Incretin treatment and risk of pancreatitis in patients with type 2 diabetes mellitus: systematic review and meta-analysis of randomised and non-randomised studies. BMF 348: g2366.

Linnebjerg, H., Park, S., Kothare, P., Trautmann, M., Mace, K., Fineman, M. et al. (2008) Effect of exenatide on gastric emptying and relationship to 
postprandial glycemia in type 2 diabetes. Regulatory Peptides 151: 123-129.

Lipska, K., Warton, E., Huang, E., Moffet, H., Inzucchi, S., Krumholz, H. et al. (2013) HbAlc and risk of severe hypoglycemia in type 2 diabetes: the Diabetes and Aging Study. Diabetes Care 36: 3535-3542.

Lønborg, J., Kelbæk, H., Vejlstrup, N., Bøtker, H., Kim, W., Holmvang, L. et al. (2012) Exenatide reduces final infarct size in patients with ST-segmentelevation myocardial infarction and short-duration of ischemia. Circ Cardiovasc Interv 5: 288-295.

Lorenz, M., Pfeiffer, C., Steinstraessner, A., Becker, R., Ruetten, H., Ruus, P. et al. (2013) Effects of lixisenatide once daily on gastric emptying in type 2 diabetes - relationship to postprandial glycaemia. Regulatory Peptides 185: 1-8.

Madsbad, S. (2014) The role of glucagon-like peptide-1 impairment in obesity and potential therapeutic implications. Diabetes Obes Metab 16: 9-21.

Mannucci, E. and Dicembrini, I. (2012) Incretinbased therapies and cardiovascular risk. Curr Med Res Opin 28: 715-721.

Mathieu, C., Rodbard, H., Cariou, B., Handelsman, Y., Philis-Tsimikas, A., Ocampo Francisco, A. et al. (2014) A comparison of adding liraglutide versus a single daily dose of insulin aspart to insulin degludec in subjects with type 2 diabetes (BEGIN: VICTOZA ADD-ON). Diabetes Obes Metab 16: 636-644.

Matthews, J., Stewart, M., De Boever, E., Dobbins, R., Hodge, R., Walker, S. et al. (2008) Pharmacodynamics, pharmacokinetics, safety, and tolerability of albiglutide, a long-acting glucagon-like peptide- 1 mimetic, in patients with type 2 diabetes. f Clin Endocrinol Metab 93: 4810-4817.

Matsumoto, S., Yamazaki, M., Kadono, M., Iwase, H., Kobayashi, K., Okada, H. et al. (2013) Effects of liraglutide on postprandial insulin and glucagon responses in Japanese patients with type 2 diabetes. f Clin Biochem Nutr 53: 68-72.

Mehnert, H. (2012) ISI - ein neues Kürzel in der modernen Diabetestherapie? Diabetes, Stoffwechsel und Herz 21: 186.

Meier, J. (2012) GLP-1 receptor agonists for individualized treatment of type 2 diabetes mellitus. Nat Rev Endocrinol 8: 728-742.

Meier, J. (2013) Efficacy of lixisenatide in patients with different levels of beta-cell function as assessed by C-peptide/glucose ratio. Diabetologia 56(Suppl. 1): A896.

Meier, J., Baller, B., Menge, B., Gallwitz, B., Schmidt, W. and Nauck, M. (2009) Excess glycaemic excursions after an oral glucose tolerance test compared with a mixed meal challenge and self-measured home glucose profiles: is the oGTT a valid predictor of postprandial hyperglycaemia and vice versa. Diabetes Obes Metab 11:213-222.

Meier, J., Vilsbøll, T., Donsmark, M., Hartvig, H. and Nauck, M. (2011) Greater glycaemic control is achieved with the once-daily human GLP-1 analogue liraglutide vs comparators across the continuum of estimated beta cell mass. Diabetologia 54(Suppl. 1): A795.

Mellbin, L., Rydén, L., Riddle, M., Probstfield, J., Rosenstock, J., Díaz, R. et al. (2013) Does hypoglycaemia increase the risk of cardiovascular events? A report from the ORIGIN trial. Eur Heart 7 34: 3137-3144.

Miller, M., Bonds, D., Gerstein, H., Seaquist, E., Bergenstal, R., Calles-Escandon, J. et al. (2010) The effects of baseline characteristics, glycaemia treatment approach, and glycated haemoglobin concentration on the risk of severe hypoglycaemia: post hoc epidemiological analysis of the ACCORD study. BMF 340: b5444.

Moens, K., Heimberg, H., Flamez, D., Huypens, P., Quartier, E., Ling, Z. et al. (1996) Expression and functional activity of glucagon, glucagon-like peptide I, and glucose-dependent insulinotropic peptide receptors in rat pancreatic islet cells. Diabetes 45: 257-261.

Monami, M., Dicembrini, I., Mannucci, E. (2014a) Dipeptidyl peptidase- 4 inhibitors and pancreatitis risk: a meta-analysis of randomized clinical trials. Diabetes Obes Metab 16: 48-56.

Monami, M., Dicembrini, I., Kundisova, L., Zannoni, S., Nreu, B. and Mannucci, E. (2014b) A metaanalysis of the hypoglycaemic risk in randomized controlled trials with sulphonylureas in patients with type 2 diabetes. Diabetes Obes Metab 16: 833-840.

Monami, M., Dicembrini, I., Nardini, C., Fiordelli, I. and Mannucci, E. (2014c) Glucagon-like peptide-1 receptor agonists and pancreatitis: a meta-analysis of randomized clinical trials. Diabetes Res Clin Pract 103: 269-275.

Monnier, L., Colette, C. and Boniface, H. (2006) Contribution of postprandial glucose to chronic hyperglycaemia: from the 'glucose triad' to the trilogy of 'sevens'. Diabetes Metab 32: 2S11-2S16.

Monnier, L., Colette, C., Dunseath, D. and Owens, D. (2007) The loss of postprandial glycaemic control precedes stepwise deterioration of fasting with worsening diabetes. Diabetes Care 30: 263-269.

Monnier, L., Lapinski, H. and Colette, C. (2003) Contributions of fasting and postprandial plasma glucose increments to the overall diurnal hyperglycaemia of type 2 diabetic patients: variations of increasing levels of $\mathrm{HbA}(1 \mathrm{c})$. Diabetes Care 26: 881-885. 
Müller, W., Faloona, G., Aguilar-Parada, E. and Unger, R. (1970) Abnormal alpha-cell function in diabetes. Response to carbohydrate and protein ingestion. $N$ Engl F Med 283: 109-115.

Nakata, H., Sugitani, S., Yamaji, S., Otsu, S., Higashi, Y., Ohtomo, Y. et al. (2012) Pancreatitis with pancreatic tail swelling associated with incretinbased therapies detected radiologically in two cases of diabetic patients with end-stage renal disease. Intern Med 51: 3045-3049.

Nathan, D., Cleary, P., Backlund, J., Genuth, S., Lachin, J., Orchard, T. et al. (2005) Intensive diabetes treatment and cardiovascular disease in patients with type 1 diabetes. N Engl f Med 353: 2643-2653.

Nathan, D. DCCT/EDIC Research Group (2014) The diabetes control and complications trial/epidemiology of diabetes interventions and complications study at 30 years: overview. Diabetes Care 37: 9-16.

Nathanson, D., Ullman, B., Löfström, U., Hedman, A., Frick, M., Sjöholm, A. et al. (2012) Effects of intravenous exenatide in type 2 diabetic patients with congestive heart failure: a double-blind, randomised controlled clinical trial of efficacy and safety.

Diabetologia 55: 926-935.

Nationale Versorgungsleitlinie Diabetes (2014) Bundesärztekammer (BÄK), Kassenärztliche Bundesvereinigung (KBV), Arbeitsgemeinschaft der Wissenschaftlichen Medizinischen Fachgesellschaften (AWMF). Nationale VersorgungsLeitlinie Therapie des Typ-2-Diabetes - Leitlinien-Report. Version 1.0. Available at: http://www.versorgungsleitlinien. de.diabetes2/dm2_therapie (accessed 10 October 2014).

Nauck, M. (2013) A critical analysis of the clinical use of incretin-based therapies: the benefits by far outweigh the potential risks. Diabetes Care 36: 2126-2132.

Nauck, M., Baranov, O., Ritzel, R. and Meier, J. (2013) Do current incretin mimetics exploit the full therapeutic potential inherent in GLP-1 receptor stimulation? Diabetologia 56: 1878-1883.

Nauck, M. and Meier, J. (2011) Pharmacotherapy: GLP-1 analogues and insulin: sound the wedding bells? Nat Rev Endocrinol 7: 193-195.

Nauck, M. and Meier, J. (2014) Pancreatitis and incretin-based drugs: clarity or confusion? Lancet Diabetes Endocrinol 2: 92-93.

Nauck, M., Weinstock, R., Umpierrez, G., Guerci, B., Skrivanek, Z. and Milicevic, Z. (2014) Efficacy and safety of dulaglutide versus sitagliptin after 52 weeks in type 2 diabetes in a randomized controlled trial (AWARD-5). Diabetes Care 37: 2149-2158.

Østoft, S., Bagger, J., Hansen, T., Pedersen, O., Holst, J. and Knop, F. et al. (2014a) Incretin effect and glucagon responses to oral and intravenous glucose in patients with maturity onset diabetes of the young - type 2 and type 3. Diabetes 63: 2838-2844.

Østoft, S., Bagger, J., Hansen, T., Pedersen, O., Faber, J., Holst, J. et al. (2014b) Glucose-lowering effects and low risk of hypoglycemia in patients with maturity-onset diabetes of the young when treated with a GLP-1 receptor agonist: a double-blind, randomized, crossover trial. Diabetes Care 37: 1797-805.

Owens, D., Luzio, S., Sert-Langeron, C. and Riddle, M. (2011) Effects of initiation and titration of a single preprandial dose of insulin glulisine while continuing titrated insulin glargine in type 2 diabetes: a 6-month 'proof-of-concept' study. Diabetes Obes Metab 13: 1020-1027.

Oyama, J.1., Higashi, Y. and Node, K. (2014) Do incretins improve endothelial function? Cardiovasc Diabetol 13: 21.

Patel, A., MacMahon, S., Chalmers, J., Neal, B., Billot, L., Woodward, M. et al. (2008) Intensive blood glucose control and vascular outcomes in patients with type 2 diabetes. N Engl F Med 358: 2560-2572.

Pennartz, C., Schenker, N., Menge, B., Schmidt, W., Nauck, M. and Meier, J. (2011) Chronic reduction of fasting glycemia with insulin glargine improves first- and second-phase insulin secretion in patients with type 2 diabetes. Diabetes Care 34: 2048-2053.

Pistrosch, F., Köhler, C., Schaper, F., Landgraf, W., Forst, T. and Hanefeld, M. (2013) Effects of insulin glargine versus metformin on glycemic variability, microvascular and beta-cell function in early type 2 diabetes. Acta Diabetol 50: 587-595.

Pratley, R., Nauck, M., Barnett, A., Feinglos, M., Ovalle, F., Harman-Boehm, I. et al. (2014) Onceweekly albiglutide versus once-daily liraglutide in patients with type 2 diabetes inadequately controlled on oral drugs (HARMONY 7): a randomised, openlabel, multicentre, non-inferiority phase 3 study.

Lancet Diabetes Endocrinol 2: 289-297.

Pratley, R. and Weyer, C. (2001) The role of impaired early insulin secretion in the pathogenesis of type II diabetes mellitus. Diabetologia 44: 929-945.

Raccah, D., Lin, J., Wang, E., Germé, M., Perfetti, R., Bonadonna, R. et al. (2014) Once-daily prandial lixisenatide versus once-daily rapid-acting insulin in patients with type 2 diabetes mellitus insufficiently controlled with basal insulin: analysis of data from five randomized, controlled trials. $\mathcal{F}$ Diabetes Complications 28: 40-44.

Ratner, R., Rosenstock, J., Boka, G. and Silvestre, L. (2009) Post-meal pharmacodynamic profile of AVE0010, a once-daily GLP-1 receptor agonist, in patients with type 2 diabetes inadequately controlled on metformin. Diabetologia 52(Suppl. 1): A131. 
Raz, I., Wilson, P., Strojek, K., Kowalska, I., Bozikov, V., Gitt, A. et al. (2009) Effects of prandial versus fasting glycemia on cardiovascular outcomes in type 2 diabetes: the HEART2D trial. Diabetes Care 32: 381-386.

Reid, T. (2013) Practical use of glucagon-like peptide-1 receptor agonist therapy in primary care. Clin Diab 31: 148-157.

Richards, P., Parker, H., Adriaenssens, A., Hodgson, J., Cork, S., Trapp, S. et al. (2014) Identification and characterization of GLP-1 receptor-expressing cells using a new transgenic mouse model. Diabetes 63: 1224-1233.

Riddle, M., Ahmed, A., Basu, A., Aroda, V. and Ratner, R. (2010) Metformin + exenatide + basal insulin: reaching $\mathrm{A} 1 \mathrm{c}<6.5 \%$ without weight-gain or serious hypoglycemia. Diabetes 59(Suppl. 1A): LB6.

Riddle, M., Forst, T., Aronson, R., Riddle, M., Aronson, R., Home, P. et al. (2013a) Adding oncedaily lixisenatide for type 2 diabetes inadequately controlled by established basal insulin: a 24 -week, randomized, placebo-controlled comparison (GetGoal-L). Diabetes Care 36: 2489-2496.

Riddle, M., Forst, T., Aronson, R., Sauque-Reyna, L., Souhami, E., Silvestre, L. et al. (2013b) Adding once-daily lixisenatide for type 2 diabetes inadequately controlled with newly initiated and continuously titrated basal insulin glargine: a 24-week, randomized, placebo-controlled study (GetGoal-Duo 1). Diabetes Care 36: 2497-2503.

Robinson, L., Holt, T., Rees, K., Randeva, H. and O'Hare, J. (2013) Effects of exenatide and liraglutide on heart rate, blood pressure and body weight: systematic review and meta-analysis. BMF Open 3: pii: e001986.

Rohrer, S., Menge, B., Grüber, L., Deacon, C., Schmidt, W., Veldhuis, J. et al. (2012) Impaired crosstalk between pulsatile insulin and glucagon secretion in prediabetic individuals. $\mathcal{F}$ Clin Endocrinol Metab 97: E791-E795.

Rosenstock, J., Fonseca, V., Gross, J., Ratner, R., Ahrén, B., Chow, F. et al. (2014a) Advancing basal insulin replacement in type 2 diabetes inadequately controlled with insulin glargine plus oral agents: a comparison of adding albiglutide, a weekly GLP-1 receptor agonist, versus thrice-daily prandial insulin lispro. Diabetes Care 37: 2317-2325.

Rosenstock, J., Hanefeld, M., Shamanna, P., Min, K., Boka, G., Miossec, P. et al. (2014b) Beneficial effects of once-daily lixisenatide on overall and postprandial glycemic levels without significant excess of hypoglycemia in type 2 diabetes inadequately controlled on a sulfonylurea with or without metformin (GetGoal-S). F Diabetes Complications 28: 386-392.

Rosenstock, J., Raccah, D., Korányi, L., Maffei, L., Boka, G., Miossec, P. et al. (2013) Efficacy and safety of lixisenatide once daily versus exenatide twice daily in type 2 diabetes inadequately controlled on metformin: a 24-week, randomized, open-label, active-controlled study (GetGoal-X). Diabetes Care 36: 2945-2951.

Rosenstock, J., Shenouda, S., Bergenstal, R., Buse, J., Glas, L., Heilmann, C. et al. (2012) Baseline factors associated with glycemic control and weight loss when exenatide twice daily is added to optimized insulin glargine in patients with type 2 diabetes. Diabetes Care 35: 955-958.

Rothe, U., Verlohren, H.-J., Scholz, G.H. and Schulze, J. (2010) New Practical Guidelines for Type 2 Diabetes mellitus in Saxony -Therapy Recommendations for Physicians. Diabetes aktuell 8: 213-217.

Schmidt, W., Siegel, E. and Creutzfeldt, W. (1985) Glucagon-like peptide-1 but not glucagon-like peptide-2 stimulates insulin release from isolated rat pancreatic islets. Diabetologia 28: 704-707.

Scholz, G. (2010) BOT-Basal(insulin) unterstützte orale Therapie bei Diabetes mellitus Typ 2 -

Pathophysiologisch begründete Therapie bei MetabolischVaskulärem Syndrom (MVS). UNI-MED Verlag AG, Bremen.

Schopman, J., Simon, A., Hoefnagel, S., Hoekstra, J., Scholten, R. and Holleman, F. (2014) The incidence of mild and severe hypoglycaemia in patients with type 2 diabetes mellitus treated with sulfonylureas: a systematic review and meta-analysis. Diabetes Metab Res Rev 30: 11-22.

Seino, Y., Min, K., Niemoeller, E. and Takami, A. (2012) Randomized, double-blind, placebo controlled trial of the once-daily GLP-1 receptor agonist lixisenatide in Asian patients with type 2 diabetes insufficiently controlled on basal insulin with or without a sulfonylurea (GetGoal-L-Asia). Diabetes Obes Metab 14: 910-917.

Shah, P., Vella, A., Basu, A., Basu, R., Schwenk, W. and Rizza, R. (2000) Lack of suppression of glucagon contributes to postprandial hyperglycemia in subjects with type 2 diabetes mellitus. $\mathcal{F}$ Clin Endocrinol Metab 85: 4053-4059.

Shao, N., Kuang, H., Hao, M., Gao, X., Lin, W. and Zou, W. (2014) Benefits of exenatide on obesity and non-alcoholic fatty liver disease with elevated liver enzymes in patients with type 2 diabetes. Diabetes Metab Res Rev 30: 521-529.

Stahn, A., Pistrosch, F., Ganz, X., Teige, M., Koehler, C., Bornstein, S. et al. (2014) Relationship between hypoglycemic episodes and ventricular arrhythmias in patients with type 2 diabetes and cardiovascular diseases: silent hypoglycemias and silent arrhythmias. Diabetes Care 37: 516-520. 
Stratton, I., Adler, A., Neil, H., Matthews, D., Manley, S., Cull, C. et al. (2000) Association of glycaemia with macrovascular and microvascular complications of type 2 diabetes (UKPDS 35): prospective observational study. BMF 321: 405412.

Thompson, A., Vande Griend, J., Linnebur, S. and Saseen, J. (2013) Evaluation of type 2 diabetes mellitus medication management and control in older adults. Consult Pharm 28: 296-306.

Tibaldi, J. (2014) Combination therapy to achieve glycemic goals: advantages of adding incretin-based therapies to insulin in patients with type 2 diabetes mellitus. Am F Med Sci 347: 491-501.

Tobin, G., Cavaghan, M., Hoogwerf, B. and McGill, J. (2012) Addition of exenatide twice daily to basal insulin for the treatment of type 2 diabetes: clinical studies and practical approaches to therapy. Int $\mathcal{F}$ Clin Pract 66:1147-1157.

Tschöpe, D., Hanefeld, M., Meier, J., Gitt, A., Halle, M., Bramlage, P. et al. (2013) The role of co-morbidity in the selection of antidiabetic pharmacotherapy in type-2 diabetes. Cardiovasc Diabetol 12: 62.

Turner, L., Nartey, D., Stafford, R., Singh, S. and Alexander, G. (2014) Ambulatory treatment of type 2 diabetes in the U.S., 1997-2012. Diabetes Care 37: 985-992.

Turner, R., Holman, R., Cull, C., Stratton, I., Matthews, D., Frighi, V. et al. (1998) Intensive blood-glucose control with sulphonylureas or insulin compared with conventional treatment and risk of complications in patients with type 2 diabetes (UKPDS 33). Lancet 352: 837-853.

Tushuizen, M., Bunck, M., Pouwels, P., van Waesberghe, J., Diamant, M. and Heine, R. (2006) Incretin mimetics as a novel therapeutic option for hepatic steatosis. Liver Int 26: 1015-1017.

Umpierrez, G., Povedano, S., Manghi, F., Shurzinske, L. and Pechtner, V. (2014) Efficacy and safety of dulaglutide monotherapy versus metformin in type 2 diabetes in a randomized controlled trial (AWARD-3). Diabetes Care. 37: 2168-2176.

Unger, J. (2013) Rationale use of GLP-1 receptor agonists in patients with type 1 diabetes. Curr Diab Rep 13: 663-668.

Unger, R., Aguilar-Parada, E., Müller, W. and Eisentraut, A. (1970) Studies of pancreatic alpha cell function in normal and diabetic subjects. $\mathcal{F}$ Clin Invest 49: 837-848.

Varadhan, L., Humphreys, T., Hariman, C., Walker, A. and Varughese, G. (2011) GLP-1 agonist treatment: implications for diabetic retinopathy screening. Diabetes Res Clin Pract 94: e68-e71.

Varadhan, L., Humphreys, T., Walker, A. and Varughese, G. (2014) The impact of improved glycaemic control with GLP-1 receptor agonist therapy on diabetic retinopathy. Diabetes Res Clin Pract 103: e37-e39.

Vidal, J. (2013) Lixisenatide - a new glucagon-like peptide-1 receptor agonist in the treatment of type 2 diabetes. European Endocrinol 9: 76-81.

Vilsbøll, T., Christensen, M., Junker, A., Knop, F. and Gluud, L. (2012) Effects of glucagon-like peptide-1 receptor agonists on weight loss: systematic review and meta-analyses of randomised controlled trials. BMF 344: d7771.

Vora, J. (2013) Combining incretin-based therapies with insulin: realizing the potential in type 2 diabetes. Diabetes Care 36(Supp1. 2): S226-S232.

Williams, M. and Garg, R. (2014) Glycemic management in ESRD and earlier stages of CKD. Am J Kidney Dis 63(Suppl. 2): S22-S38.

Woodward, H. and Anderson, S. (2014) Once-weekly albiglutide in the management of type 2 diabetes: patient considerations. Patient Prefer Adherence 8: 789-803.

Wu, S., Sun, F., Zhang, Y., Yang, Z., Hong, T., Chen, Y. et al.(2014) The cardiovascular effects of glucagon-like peptide- 1 receptor agonists: a trial sequential analysis of randomized controlled trials. J Clin Pharm Ther 39: 7-13.

Wysham, C., Blevins, T., Arakaki, R., Colon, G. and Garcia, P. Atisso, C. et al. (2014) Efficacy and safety of dulaglutide added onto pioglitazone and metformin versus exenatide in type 2 diabetes in a randomized controlled trial (AWARD-1). Diabetes Care 37: 2159-2167.

Yki-Järvinen, H., Juurinen, L., Alvarsson, M., Bystedt, T., Caldwell, I., Davies, M. et al. (2007) Initiate insulin by aggressive titration and education (INITIATE): a randomized study to compare initiation of insulin combination therapy in type 2 diabetic patients individually and in groups. Diabetes Care 30: 1364-1369.

Zhang, H., Zhang, X., Hu, C. and Lu, W. (2012) Exenatide reduces urinary transforming growth factor$\beta 1$ and type IV collagen excretion in patients with type 2 diabetes and microalbuminuria. Kidney Blood Press Res 35: 483-488.

Zoungas, S., Chalmers, J., Ninomiya, T., Li, Q., Cooper, M., Colagiuri, S. et al. (2012) Association of $\mathrm{HbA} 1 \mathrm{c}$ levels with vascular complications and death in patients with type 2 diabetes: evidence of glycaemic thresholds. Diabetologia 55: 636-643.
Visit SAGE journals online http://tae.sagepub.com

@SAGE journals 